لالسفلةمن بوالي خيط الخامل المختلفة بالمصلع لإنتاج ملابس خارجية للسيدك تشقق الأداء

$$
\text { الماليف والمالهر الجمالي }
$$

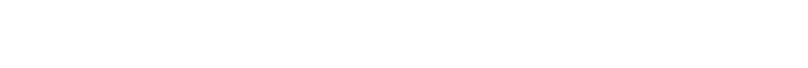

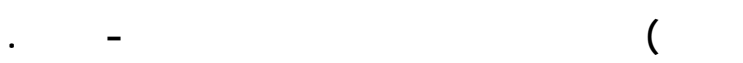

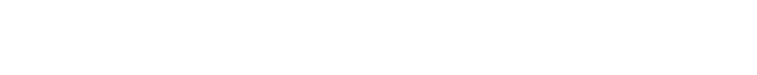

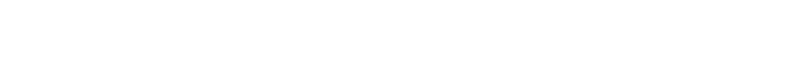

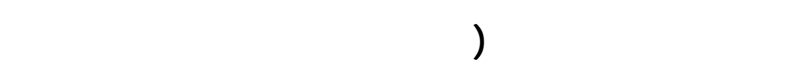

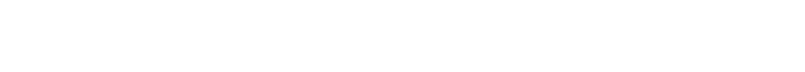
والتأثيرات الزخرفية). وكلت أهم النتائج ما يلي:

- هقت أفهشة الملابس الخارجية للسيدلت المنتجةمن بـ بولي

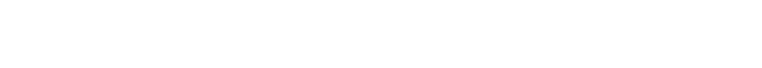

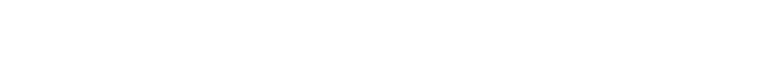

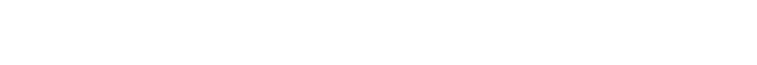

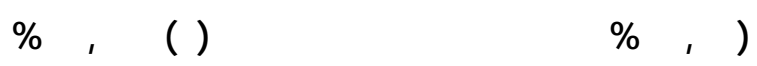

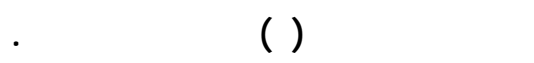

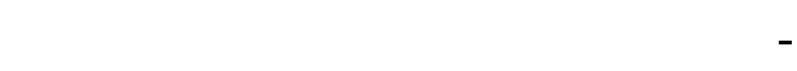

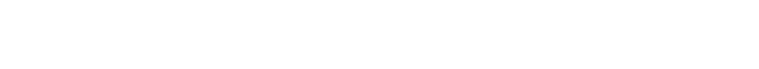

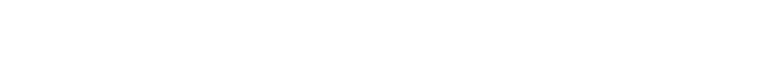

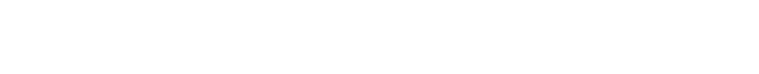

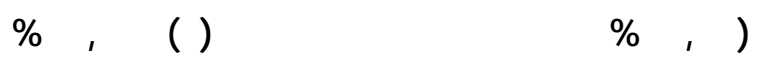

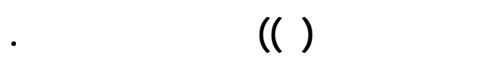

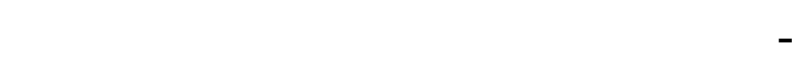

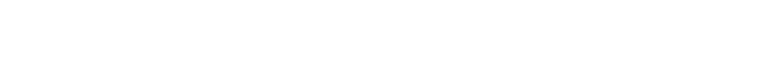
متوطلت فيم المككمن لالمحور الثالثمن محاور القيم

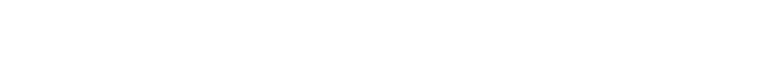

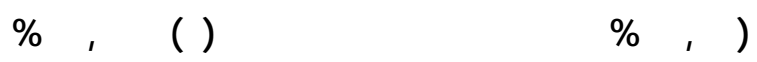

بالنبة اللعينة رقم (ع) وه نسبة مرفهمة.

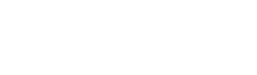

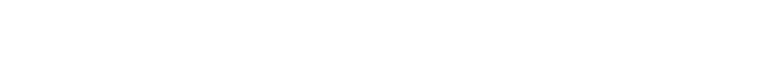
المختلفة بالمصلع لإنتاج ملابس خارجية للسيدلت تهقق الأداء

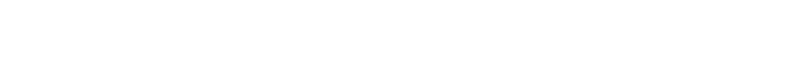

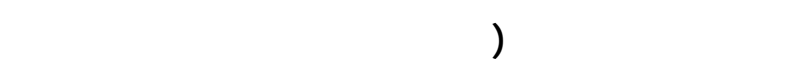
وألولن، ونمر خيطا) مختلفة لقديم نوعيلت من ألهشة السيدلت الخارجية لالمُنتهلت ذالت قيم جمالية متنوعة وموالهفلت تنهقق التأثير الإيجالي عل الخواه الجمالية الجمالية والظليفية، وكذا الجلب لافتصامي.

وقد مم إنتاج عينت الخيط المزوبة وعسها(0) من الخيوا

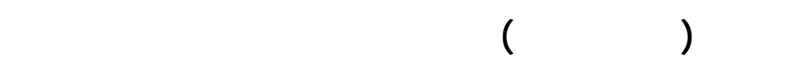

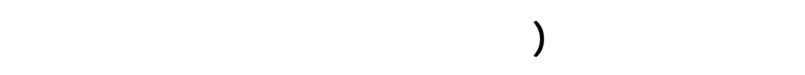

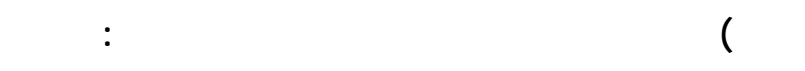

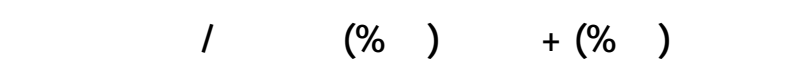

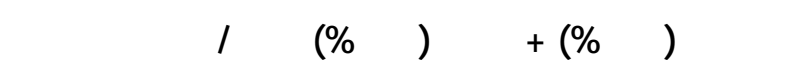

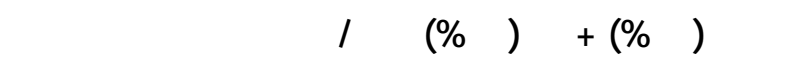

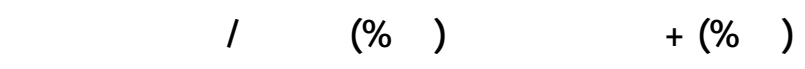

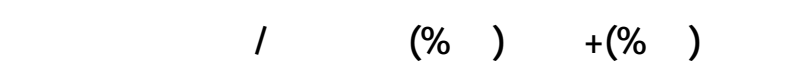
كلحمات وذك بمصنع الزالوي بمدينة السلام - الفاهرة.

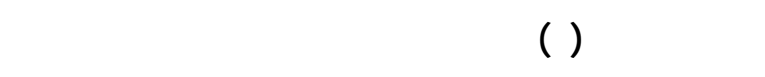

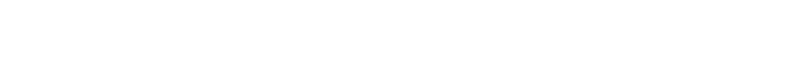

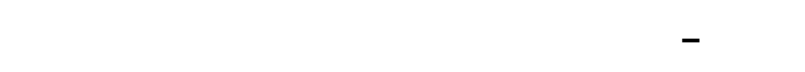
إنتاج أفهشة في بالغرض الخليف والجمالي والفتصادي وفي فس الوقت تتنم بالابتكاربة.

وأجربت بهض الختبارل المعملية عل الأفشة المنتج

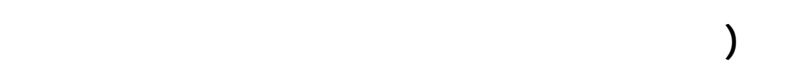

أأستاذ مساعد بقم علوم الأغنية لهعبة الاقتصاد المنزلي الريفي) -

كلية الزراعة - جلمعة الزقازيق

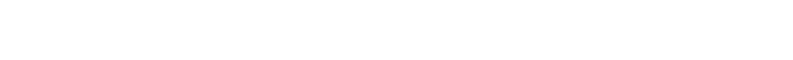


المختلفة التي تتحدد مسب نمرة الخيط ومواصفاته وطبيع ة

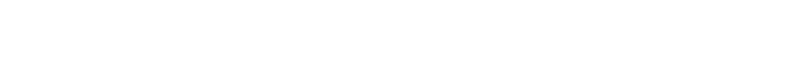

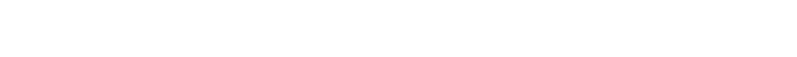

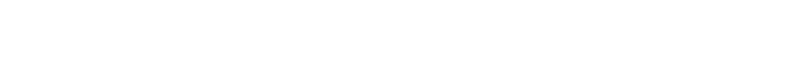

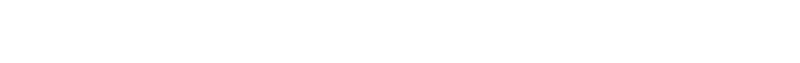

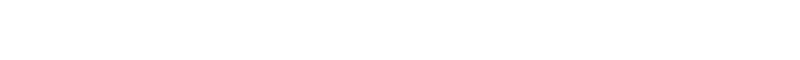

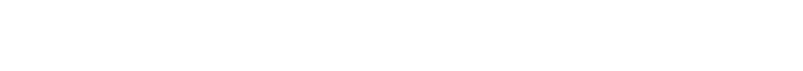

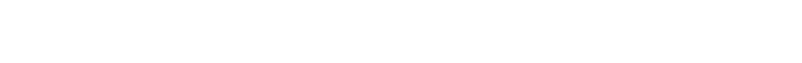

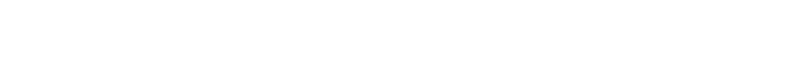
والاسقادة منها في إنتاج نوعيلت من الأفمشة الزخرفية التي

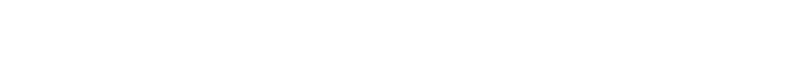

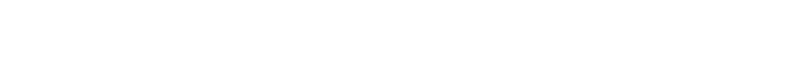
لستخدت في إنتاج هذه النوعية من الأقمشة.

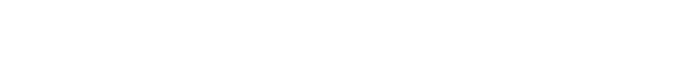

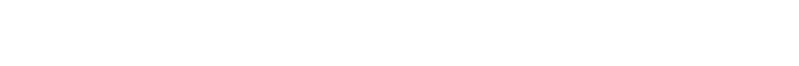

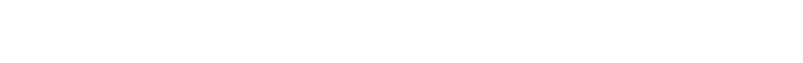
أثناء عملية النسج من فتح الفس وخلافه ولذك كلن الاتجه

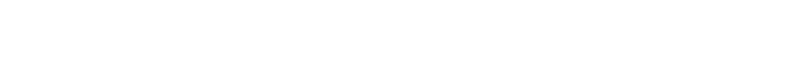
عنطريق زوي خطين مختلفن من حيث (لأساليب الغ _زل، زخيه

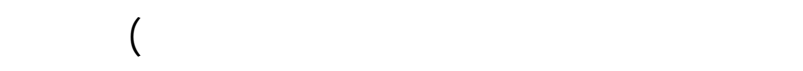
الخيوط لمتخدت في إنتاج اقمشة ذات خواص ومواصفلت ولت ولتون

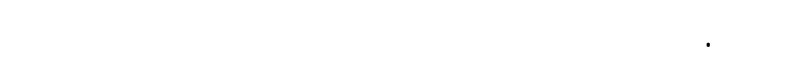

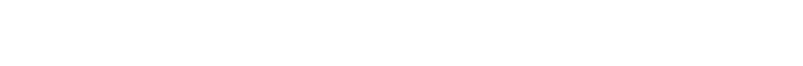

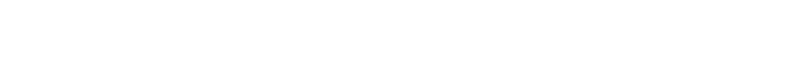
والجمالية هذا بالإضلفة إلى تحقيق الخداع البصري الـ ذي الهمي

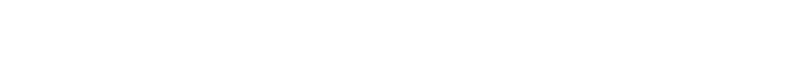
والتي تتنلبب مع أقمشة الملابس الخارجية للسيدات.

\section{مُشكالة البحث}

يم إنتاج الخي -وط ف مي الم صانع ح سب الكمي ـلت

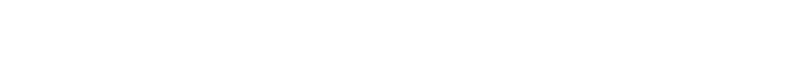

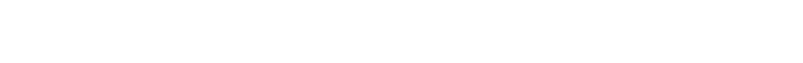

- لفهة الملابس الخارجية للسيدل المنتجةمن بولي خي -وط

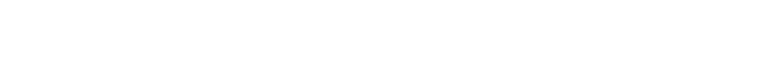

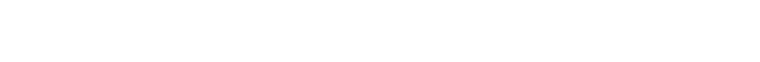

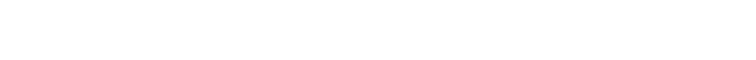

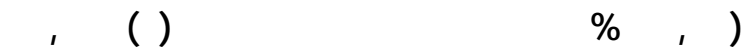
\%بالنسبة اللعينة رقم(ع) وه نسبة مرذهمة. ويمكن ترتيب المحاورف مي ضـ وومتوسد طلت فييم لـ المكممن كما يلي:عناصر التصميم، الناحية الوليفية، الناحي ة

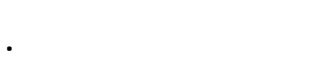

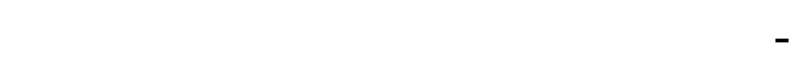

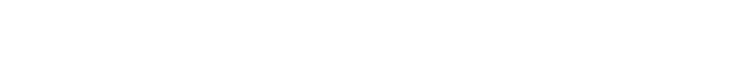

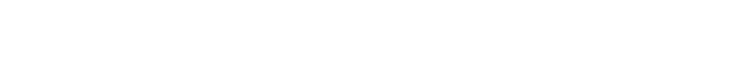
الوزن نتيجة الحتكك. - هقت المينة الرلبعة أعلى نسبة السظالة بينما العينة الثالثة والخالسة جهقتا لل نسبة السقالة. - جقت العينة الثالثة أعلل صلابة بينما جقت العينة الرلبع مة لل درجة صلابة.

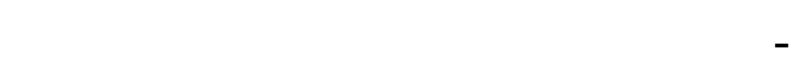

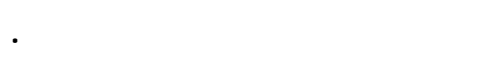

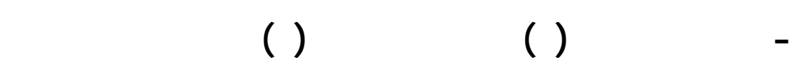

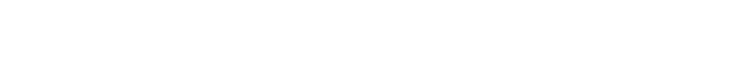
المختلفة في ضوء نتائج الختبارلت اللبيعية والميكانيكية. - وجت علافة الرتبلليه بين ترتيب المحكمن للعينت وترتيبها في ضوء ننائج الختبارت اللبيعية والميكلنيكية.

$$
\text { الفقدم - مة }
$$

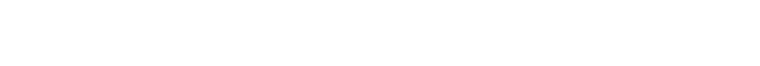

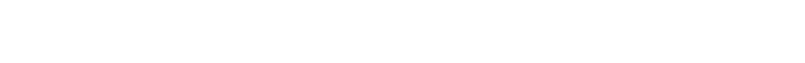
والكميت التي يرغب فيشراؤها وعلى ضوء ذل لك يق -وه

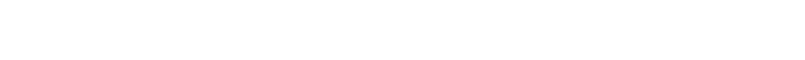
لحتسب كمية الثدوائب والعواهم التيسيم لستخلاصها ف مي الملكينات نتيجة التثغيل في المرلل المختلفة وظةرا لفاوت

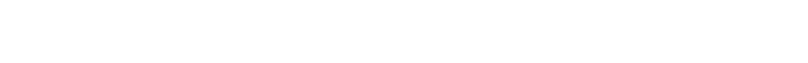


r - الإسقادة من أحد مرلل التشغل الهلمة وهي مرحل ـة

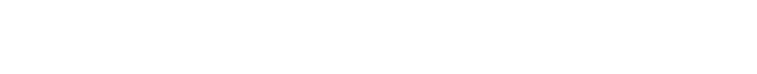
تستخدم في أقمشة للسيدات الخارجية.

ب - -الحصول على أقمشة بمواصفلت تحقق الأداء الـ ـوظيفي الذي يحقق رغبلت المُستهلكات.

ع - درلسة خواص الأفمشة المُنتجة لتحيد أفضل الأن -واع الملائمة لمابس السيدات الخارجية.

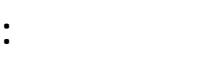

1 - تهقق أقمشة الملابس الخارجية للسيدات المنتج ـة مـ ن

بواقي خيوط الخلملت المختلفة درجة قبول ونجاح ف مي

ضوء متوسطلت نقيم المحكمين للمح يور الأول م ن

$$
\text { محاور القيم (عناصر التصميم). }
$$

r - تقهق أقمشة الملابس الخارجية للسيدات المنتج ـة م ن

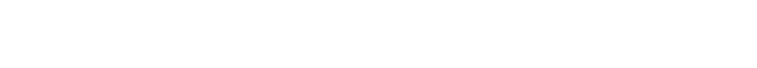

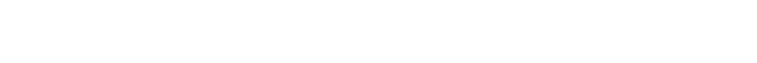
محاور القيم (لمس التصميم).

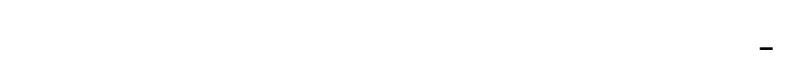

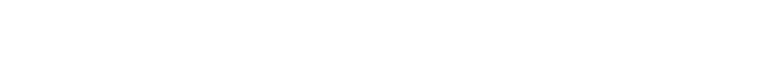

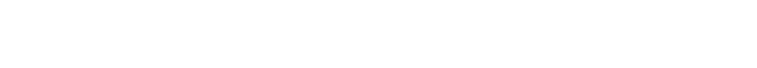
محاور القيم (النلحية الجمالية).

ع - تمقق أقمشة الملابس الخارجية للسيدات المنتج ــة مـ ن

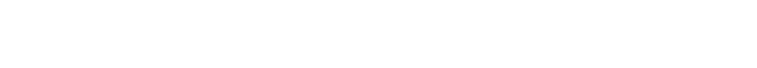

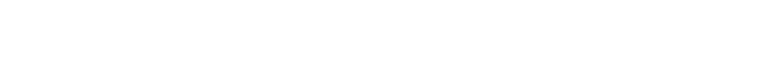
محاور القيم (النلحية الوظيفية).

0 - تمقق أقمشة الملابس الخارجية للسيدات المنتج ـة مـ من

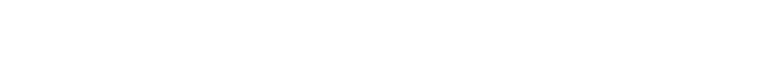

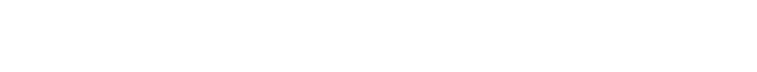
(الإجمالي).

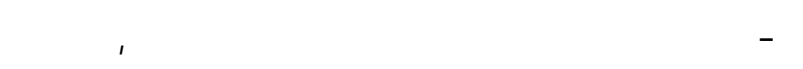
متوسطلت محاور نقيم أقم شة الملابِ س الخارجي ـة

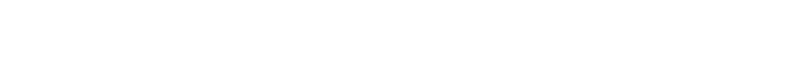

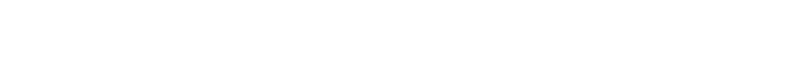

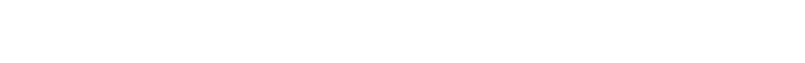

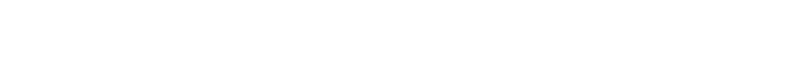

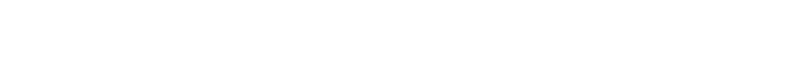

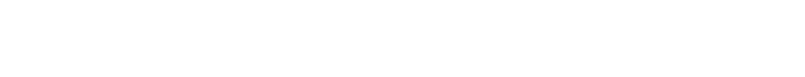
المصانع وتلافي الخسائر بإعادة تدوير هذه الخيوط، وعليه كلن لختيار موضوع البهث (الاسنقاة من +ـ -واقي خي -وطاني

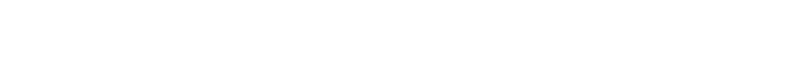
تحقق الأداء الوظيفي والمظهر الجمالي).

\section{لهمبة الجث}

\section{ترجع أهمية البهث إل الاعتبارل الآتية:} أولاً: اعتبارلت صناعية:

لستخدلم بواقي الخيوط في إنتاج لحملت مزوي مة مـ نـ (خلملت، ونسب خلط، ولساليب غزل، وألوان، ونمر خيوط)

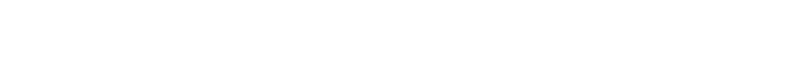

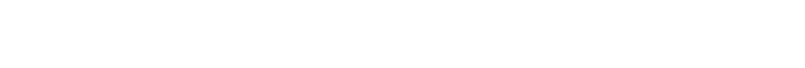

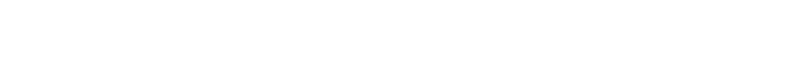

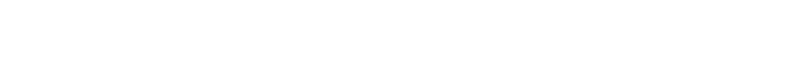

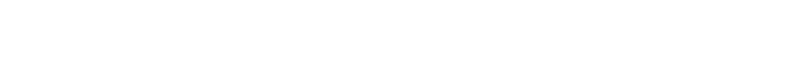
الجمالية والوظيفية للأفمشة المُنتجة.

شانيا: اعتبارل الفتصادية: الإسقاة من بواقي الخيوط في إنتاج نوعيلت من أقمشة

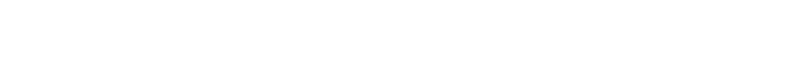

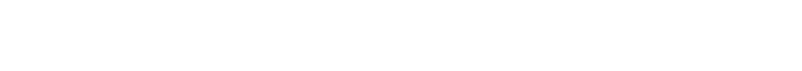

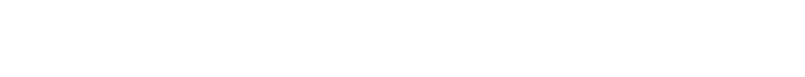
وتهقيق ربحية للمصانع.

\section{لع. لع.}

1 - لمتغلال بواقي الخيوط بالمصانع ف في إنتّ اج أقم ششة سيدك تُحةق المرككت والمصانع عائد اقتصادي. 


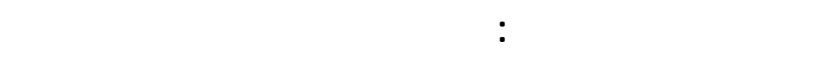

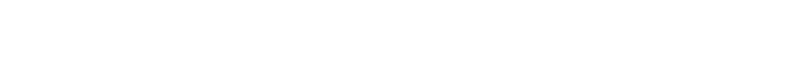
كبيرة في التخلص منها بالنسبة للمصانع.

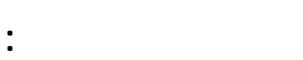
أولا:عملية زوي الخيوا:

الخط (الغزل) عبارة عن مجموء لهة مـ ن الـ شُعيرات

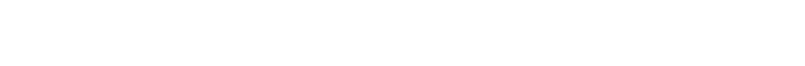

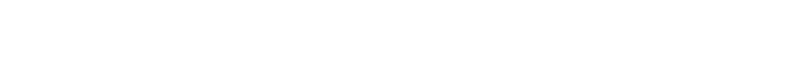
الصناعية وعملية الغزل تعرف على إنها العملية التي تعطل

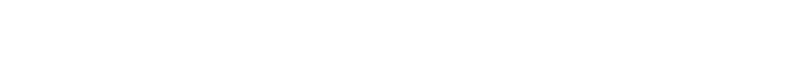

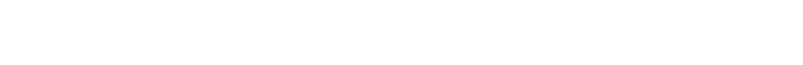

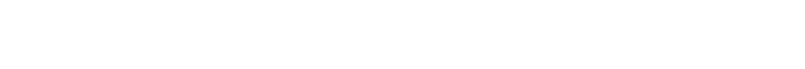

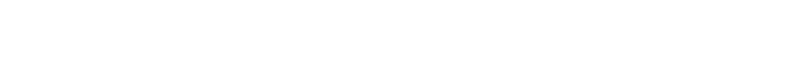

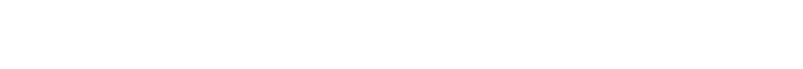

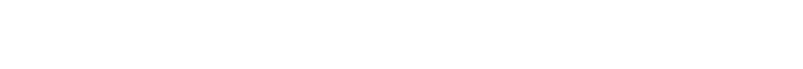

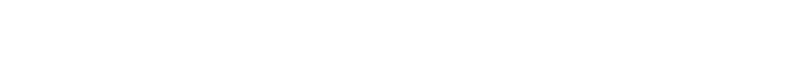

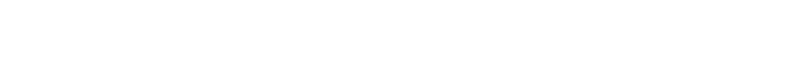

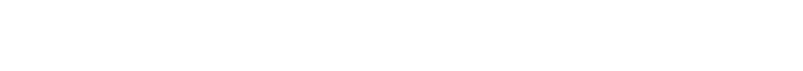

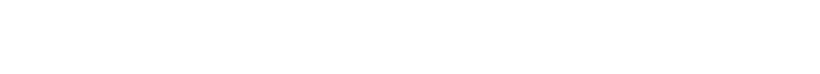
البوليستر أومع البولي لذريبليك (V).

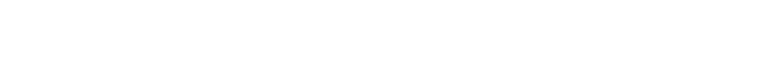

وتعطى حمج نوعى اعلي ومعالمل تخطية أفضل (َ).

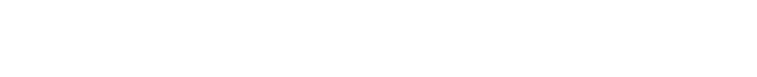
وكذك الاختلاف فيسمك الخيوط تزيد عند زويها معا كما أن كمية الزوى (عدد البرملت) في وحدة القيلس لها أهمي

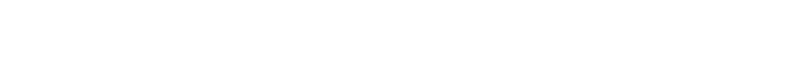
الني تعتمد على التبانن بين الخيوط المغزولة المُحتوية على اله الهظهرية والمسلمية والمرونة (r). الأهمية الصناعية للزوي:

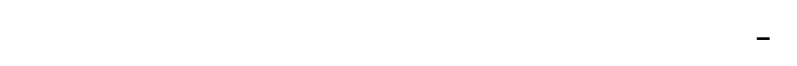

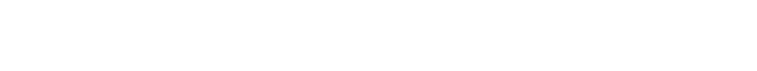

للسيدات المنتجة من بواقي خيوط الخلمك المختلفة في ضوء ققيملت المحكمين.

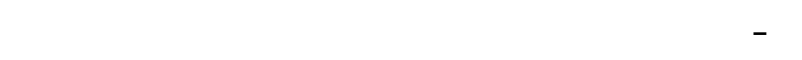

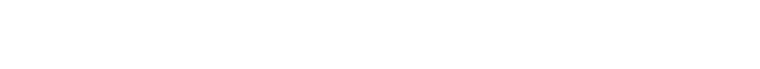

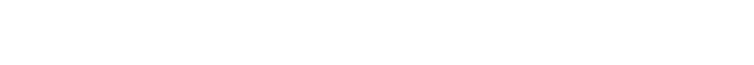
ققييمات المحكمين. ـ - توجد علاقة ارتبطيه بين ترتيب المحكم ين للعين لـ

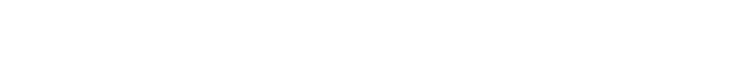
والميكلنيكية.

منهجية البه: يتع البهث المنهج التجريبي والتحليلي. الحود الزمنية البهث: لستغرق إجراء هذا البهثمشهور من يناير إلى مايو 10 · بم. لم. النعارف والمصملحلت العلمية:

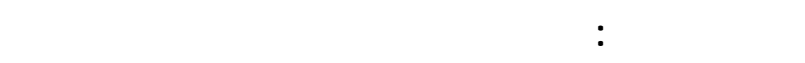
الشعيرات إلى نمرة الخيط المراد إنتلجه وإعلائه البرهم لت الت التهائ

اللازمة هسبطبيعة المستخدلم (V).

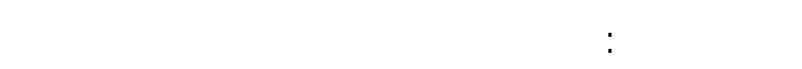

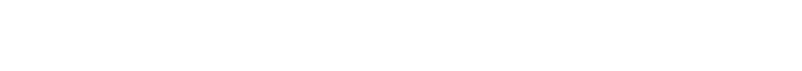

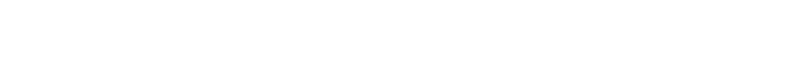
العملية كلستعاضة عن عملية التنشية (v). النعارف الإجرائية:

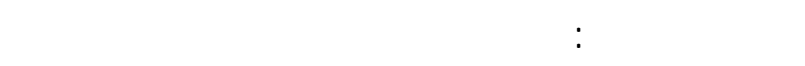

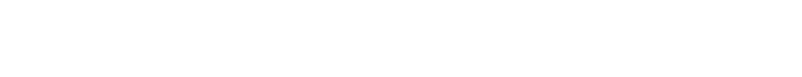
الخارجي كاللان وللشكل والمله س والخلم فة وال شثفافية والانسدالية.

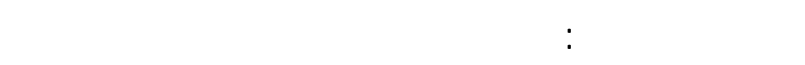

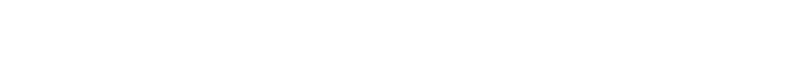

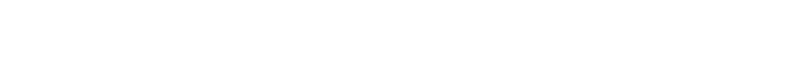

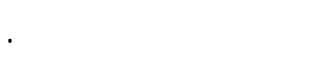




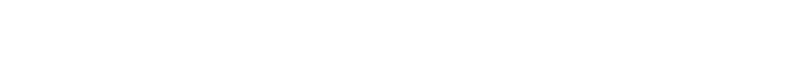

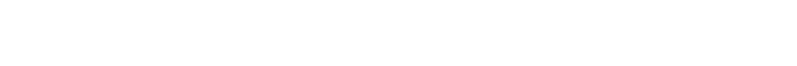

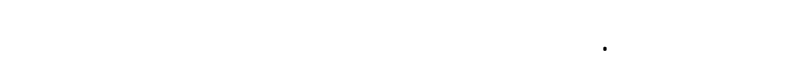

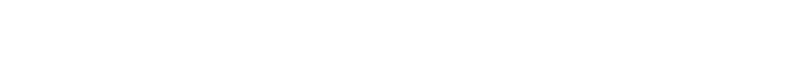

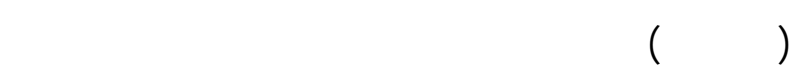
غير مستوى نتيجة الانكملاش العثوائي لخيوط اللحِمة والذي لئي

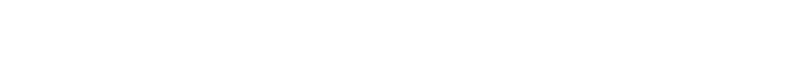

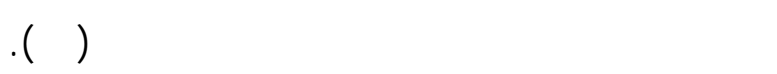

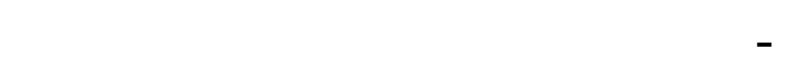
والميكانيكية للأفهشة المُنتجة:

1 -زبالةمتلنة الأفهشة: يؤثر معلمل البرم في الخيوط على قوةشد الأفمشة فبزيادة معلمل البرم تزيد متانة الأقمشة. r -فانية الأفهة للهواء : بزياةة مُعلم لـ الب ـرم ت _زداد فانية الأقمشة للهواء حيث يعتبر مُعال البرم أهم علمل

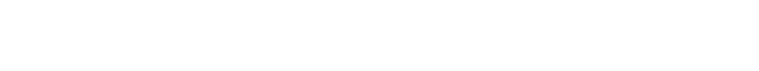
الأقمشة للهواء.

" -زبامسطك الفٔهشة: بزيادة برم الخيوط تزداد ص الابة

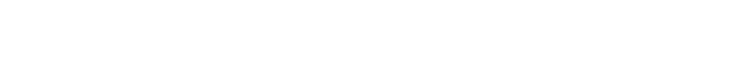
يرزداسُمك الأفمشة (7) .

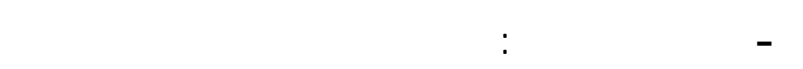
عالي ويعزى ذلك للدور الذي تلعبه البرملت في تقلي لل حرية حركة الثبعيرات المغزول منها الخيوط وبالت اللي

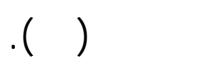

0 -زبادة النسل الفٔفشة نتيجة الزباة الصلبة: الخي -وط

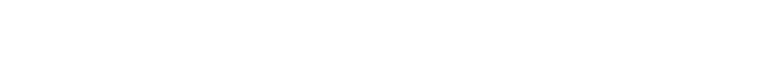

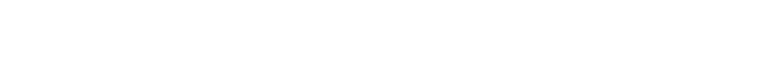

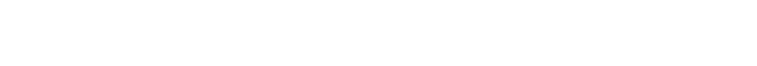

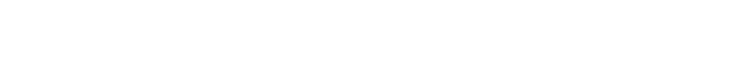
نعومة الملهس والقدرة على الانسدالية (ع ا). 7 -زبالة طقاومة الفٔفشة للكرهشة: البرمات العالية عل مى الخط تزيد من إجهاد الشعيرات مما يؤدى إلى وصولها
والانقلم صِفة ذات أهمية خاصة في الأقمثة الف لخرة حيث للفظهر العلم للقملث أهمية كبيرة.

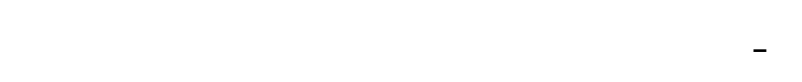
مجموعة الخيوط الفرية الدلخلة في تكوينه.

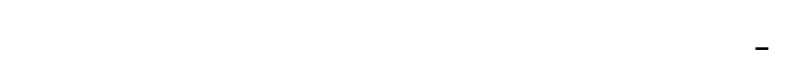
النسج (11) ع - عملية الزوى تجعل الخيط أكثر تضخما وتُطقى حجر م نوعى أعلى وتغطية أفضل. 0 - إنتاج خيوط لكثرمرونة وذك في حالة الخيوط الفردية الرفيعة. 7 - إنتاج خيوط لكثر نعومة وقد يكون الهدف منها زي الة

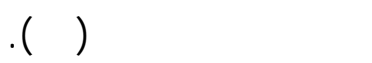

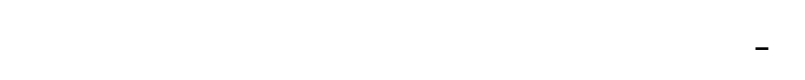
تستعل كخيوط للسداء وذلك لما تتعرض له له الخيوط من الخه إجهادات في عملية القى في بشرات المشط وعملية فتح الفس وضم اللحمة.

تأثير عملية زوي الخيطا على خواه الفٔفشة المنتجة:

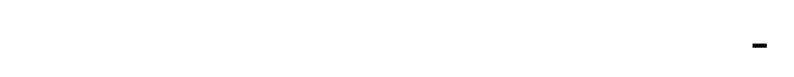
والظلفية للأفهشة المُنتجة: يُساعد تشغيل الخيوط ذات البرم العالي باللحمة أوللسداء

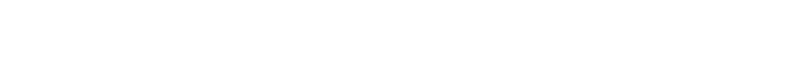

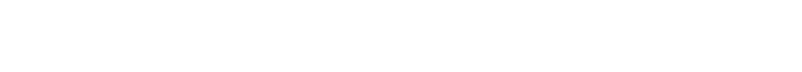
كنتيجة لتثغل ترلكيب نسجية خاصة بما يعط مع نفاني ـة

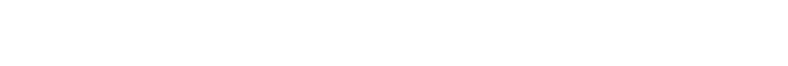

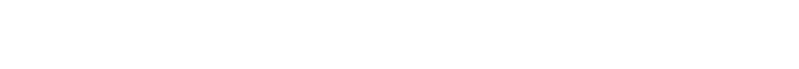
يسمح بمرور الهواء حلملاً الرطوبة من الجسم إلى الخارج

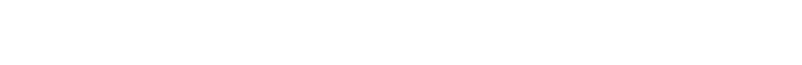
الفنيولوجية.

كما أنها تتميز بصفلت وظيفية مل عدم الاتساخ هـ ذذا بالإضفافة إله الإمسلس بالرلحة الملبية عذ ـد لـد ـتعمالها 
ومهما لختلفت مجالات لستخدلم الاقشة فانه يمكن تحدي ـ2 2 عددمن العولمل نذكرها فيما يلي:

أولا: العوللل الأدائية:

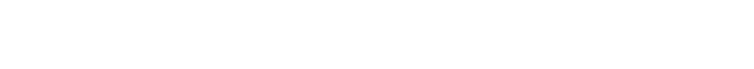

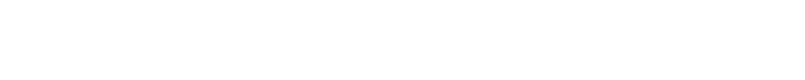

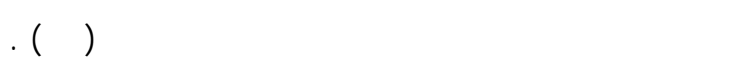

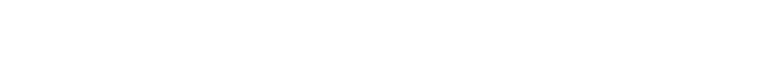

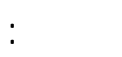
أ - الخلملت النسجية المختلفة وصفاتتها والغ -زول المتتج ـة وتأثيراتتها الزخرفية المختلفة.

ب - وظفة العل الفني والغرض من لستعمل المنتج.

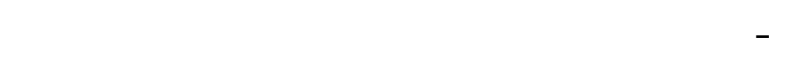
واللحمة والتعلثقات النسجية وتأثيراتها للنطحية.

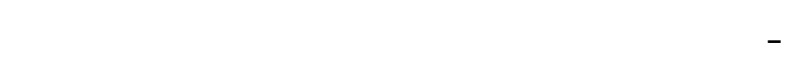
لإنتاج المنسوج ونوع التجهيز المستخدم ( ب).

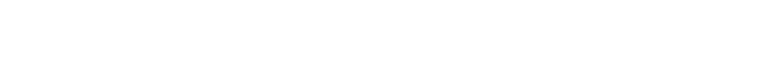

فئ هيئه الجماليةسواء المرئية أو اللونية أوالملمسية (9). غانيا: الموللم الولفية تعتبر العوامل والمطلبلت الوظفية في تصميم المنتجلت

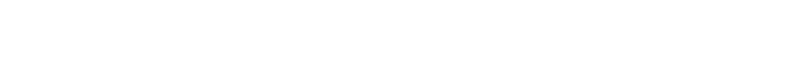
والمطلبت الوظفية المؤثرة في تصميم المنتجلت الن سسجية

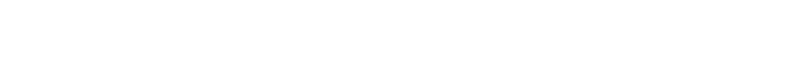

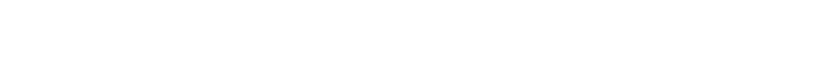

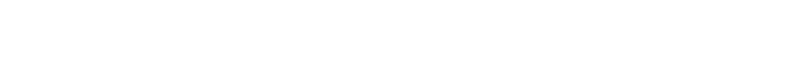

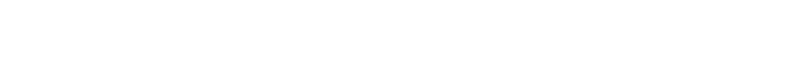

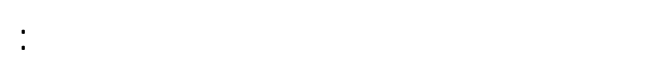
أ - وظافف لأسلسية: وهى الوظاف الأسلسية الملوب أدائها لتحقيق الغرض الاسلسى من وجود المنتج.
إلى حد الططية (لسطالة دائمة) وعنما يكون الب ـرم إمبر

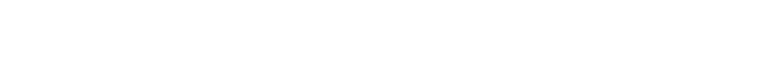
اللشعيرات دلخل الخط عند نظطة الانثناء مما يؤنى إلى يلى

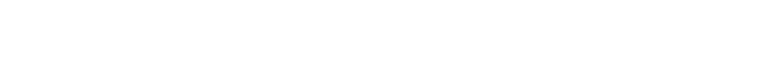

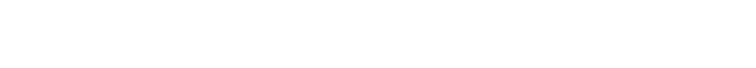

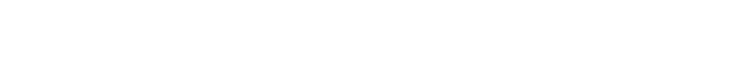

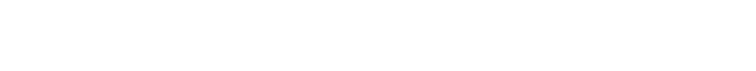
نتيجة الثي والكرمشة.

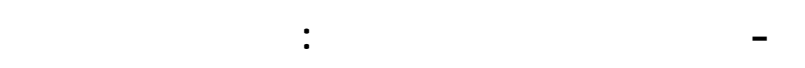

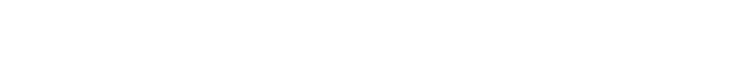
اللحمة يقل كلما ازدادت برملت خيوط اللحمة بلمنتخدالم

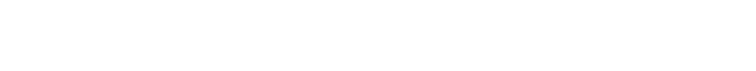
على لسطالة الأقمشة نتيجة للاسطالة الخيط.

\section{ثلنيا:ملابس اللسيدات:}

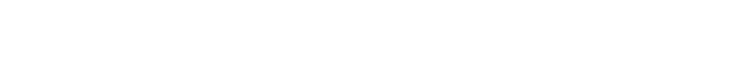

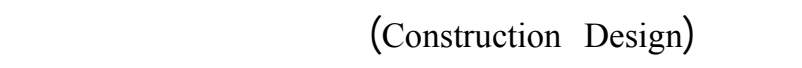

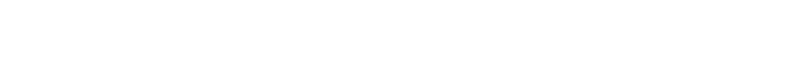

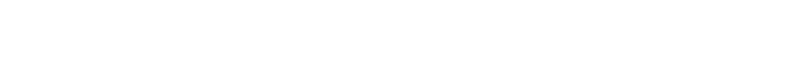
زخرفيا لا يتحدد إلامن خلال عوال المالِ تركيبه البنائي ويع 2

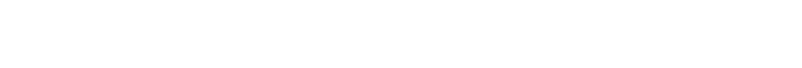

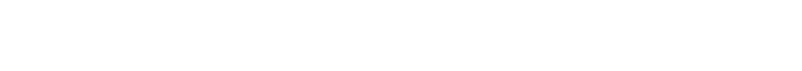
أهم العوال الني تساعد على جذب المستهاك ورواج المنتج وتحقية للجودة المنشولة.

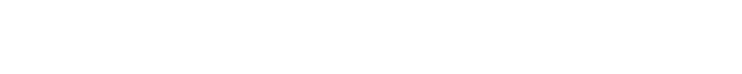

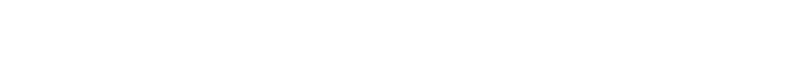

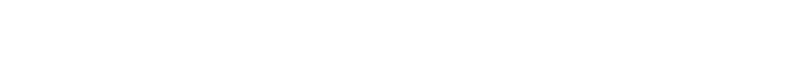

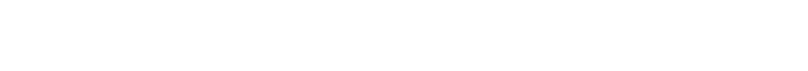

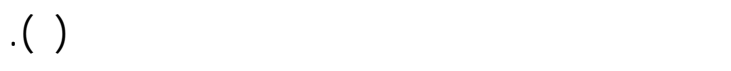

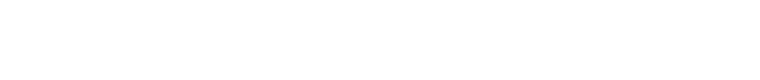

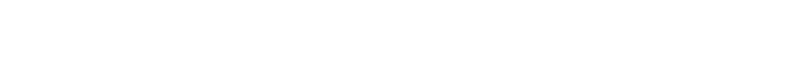
ومواصفات تشغيل وصولا إلى خ ـواص المذ ـتج النه ائي 
الأولية التجارب المعملية ولا يتسرع في تسوق منتج هـ إلا

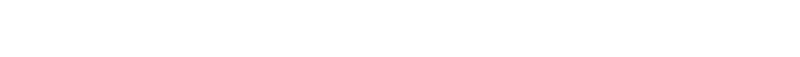
عولمل تتحكم فيسعر المنتج وهى: أ -شكل وحجم ومواصفلت التصميم الهلوب تقفيذه. ب - الخلملت النسجية المستخمة. ج - الألوان والصبغلت المستخدة. د - المعالجلت وطريقة التجهيز(1) . (1). خالساً: المولل الفسية: يربط العلمل الفسي بين أشكل معين ـة أولس ـتعمالات محدة في التصميم مجالات فنسية يكون نتيجتها الرج -وع اليال إلى العولمل التي تأثر بها الفرد في الماضي فالألوان مثلا لا تبدو لنا في تجربتنا العادية مجرد ألوان تراها العين لبل هي العي الماضي

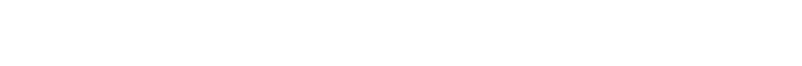
الألوان أوالهيئت التي نراها في المنتج آثارا فـ سية مـ من

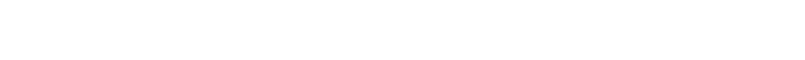

خيل كلاهماسمات ضرورية في تأثيرها الجمالي (9).

\section{عساصساً: العولل لاجتماعية (البيئة للستهلكية):}

كلما تغيرت البيئة تأثر التعبير الفني، والبيئة الاستهلكية

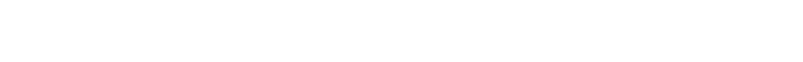

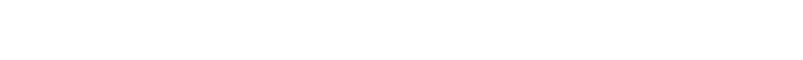

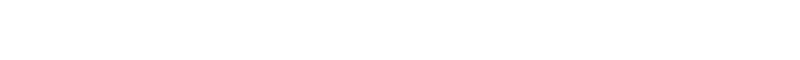

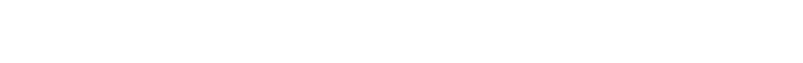
وققاليه حيث تختلف تلك العولمل وما يصلحبها من عناصر للتصميم والتي ترتبط إلى حد كبير بالثقافة والمفاهيم للسائية حيث يختلف تأثير العنصر واللون والزخرفة منشعب إله

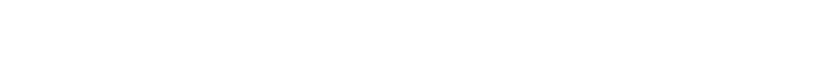
الاقتصادية لها دور واضضح على التجه التصميم من خ خلا لل

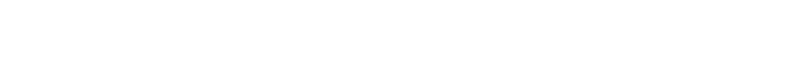
المجتمع (0).

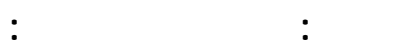

ب - وظاف ثانوية: وهى الوظاف التي تساعد في تحقي ق الوظافف الأسلسية وصولا إلى تهقيق الملائمة الوظيفية

وقد حالول علماء الفس ترتيب الحلجلت الوظيفية وتوصلوا إلى أربع مستويت وهي: 1 - - الحلجلت المنسولوجية.

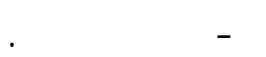

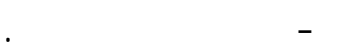

ع - الحلجلت الشخصية (0).

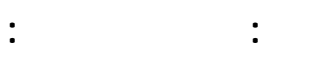
الإعسلس بالجمل هو الإس تجابة الطبيعي ـة للعلاق لت

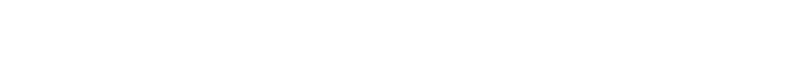

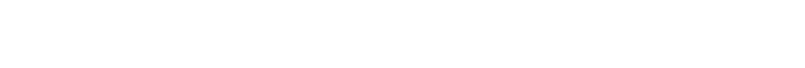

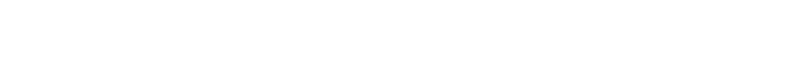

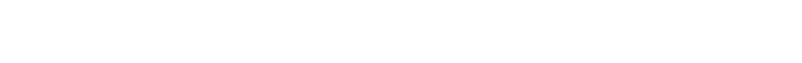

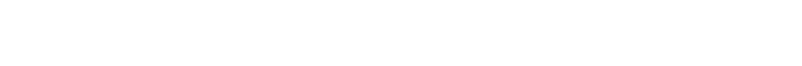
لمنتج عنمنتج لخر(10) وتعتبر القيمة الجمالية من القيم الكب ـرى ف مي العملي ـة التصميمية ولحتيلجلت المستهك حتى يمكن القول بأن وجود الجمالية تلك القيمة في اى منتج من المنتجلت هو الذي يجعله عم للا فنيا(7) (1).

\section{رلبهاً: العولل لالفتصالية:}

توجد علاقةطرية بين الابتكار التصميمي وطبيقاة هـ دلخل المظومة الإنتلجية لتحقيق عناصر الجوة والاقتصاد

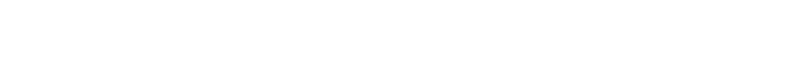

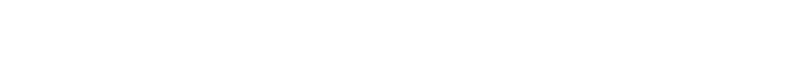
لمدى الاحتياج الذي يحققه المنتج للمستخدم (قيمة الج -ودة)

والتكلفة التي يدفعها للحصول عليها (تكلفة الجوتة) (1). لذك يجب على المصمم الإلم لم بـ الظروف الفعلي ـة واللستخدامية التي يتعرض لها المنتج ويجرى على نمانجه 


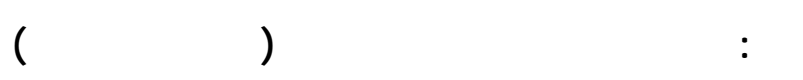

Single Yarns Specification

يوضنح جدول( () مُواصفات الخيوط الفردية المُستخدة

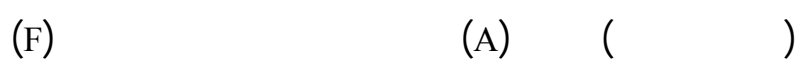

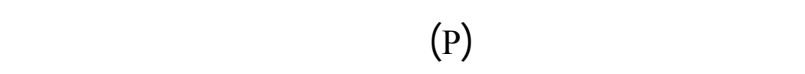

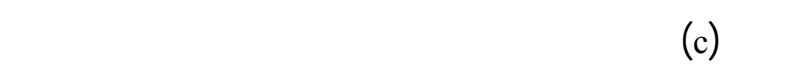
الانجليزي وكلها بواقي خيوط.

\section{ثلنياً:موالهفل ويسب الخلا للخيول المزوبة:}

مة إنتاج عينات الخيوط المزوية وعددها(0) من الخيوط الفردية (بواقي الخيوط) المتلحة بالمصانع والمنكورة ف في المينات

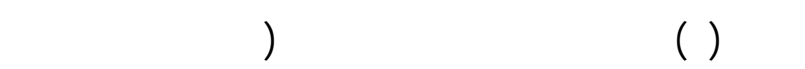

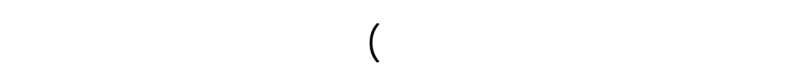

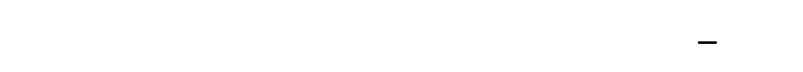
ومعادلتها بالترقيم الانجليزي، ومواصفات العينت المنتج

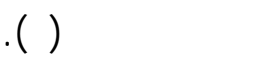
غالاًا: الموالمفلت الفنية الملكينة الزوى الحالف المستخمة: كما فع جدول (ب).

\section{رلبعأالفمشة المنتجة تهت الجمث:}

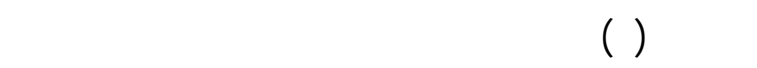

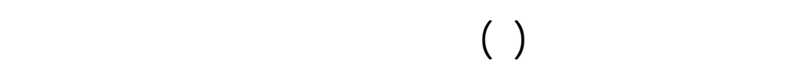
المصرية لغزل ونسج الصوف بإمبابة -القاهرة.

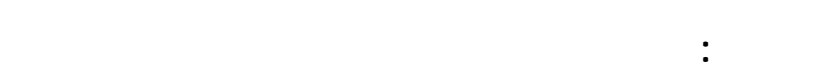

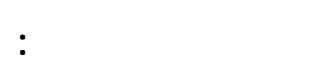

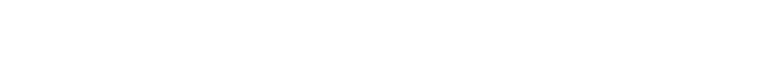

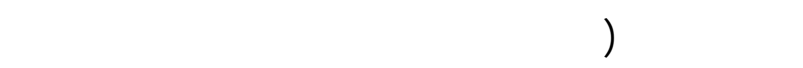

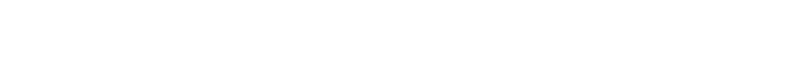

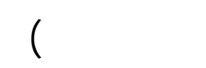

تتسم التكنولوجيا العالمية الحيثة في الصناعت النسجية

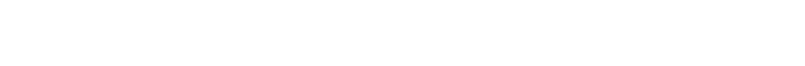

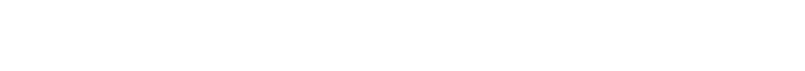
طرأت على جمبع مرلل إعداد وتفيذ المنتجلت الن سجية

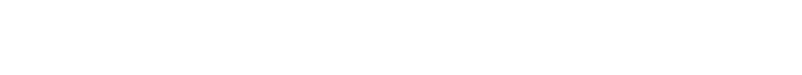

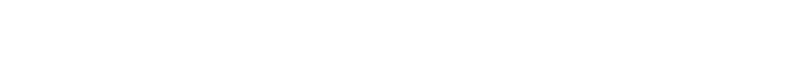
تكالف الإنتاج وذلك لعة لأسبب منها: أ - أهمية عنصر الوقت في مرلكل التثغيل المختلفة. ب - التنوع الكبير والم ـضطرد ف ي الخلم ـلت والأل _وان والتجهيزات. - التوع التير



الأذواق المختلفة والمتباينة لجمهور المستهلكين( ) .

\section{الساوب البحثي}

- تصنيف بواقي الخيوط من حي عث (النم _ر، والأل _وان، والخلمل، ولُساليب الغزل، ونسبة الخطا). - إجراء عملية زوي لبواقي الخي _وط الفردي ـة الموج -ودة بالمصانع. - لستخده الخيوط التي مت زويها والمقترحة مطل الدرلس ـة

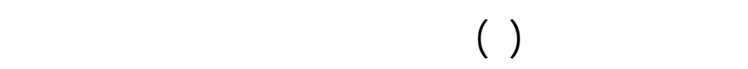
يقم الستخدالمُها كِلحْملت. - إجراء الاختبارات المعملية للعينت ممل البحث والدرلسة

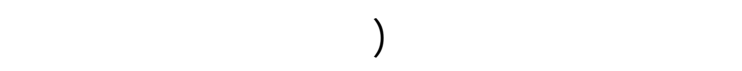

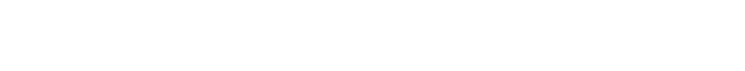
ومقاومة التمزق، والصلابة). - تصميم لستمارة لستبيلن تتضضن عناصر ولأسس التصميم والنولهي الجمالية والوظيفية للأقمشة المنتجة وءرضنها

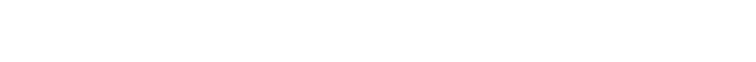
والمنسوجلت لتحكيمها وإبداء الرأي فيها.

1 - الخاملت والماكينت المستخمة والتج ارب الهملي ة والختبارل الممملية 
جدط 1.مُواهفلت الخيولا الفردية المُستخمة (ملط الريرلسة).

\begin{tabular}{|c|c|c|c|c|}
\hline اللهن & ألسلوب الغزل & النمرة Ne & نوع الخالمة & مسللل \\
\hline رصاصي & أليلف صناعية & $\mu \varepsilon$ & $\mathrm{A} \% 50+\mathrm{F} \% 50$ & 1 \\
\hline لَٔحمر & أليف صناعية & $r$. & $\mathrm{A} \% 67+\mathrm{P} \% 33$ & $r$ \\
\hline أبيضض & أليف صناعية & $r$. & A $\% 100$ & $\mu$ \\
\hline تركواز & أليلف صناعية & 17 & $\mathrm{~A} \% 60+\mathrm{F} \% 40$ & $\varepsilon$ \\
\hline ب بيج & مُبل كتلن & $\mathrm{V}$ & A $\% 60+F \% 40$ & 0 \\
\hline بيجيج & مُمُل كتلن & 10 & $\mathrm{~A} \% 50+\mathrm{F} \% 50$ & 7 \\
\hline أحمر & أليف صناعية & 17 & $\mathrm{~A} \% 67+\mathrm{P} \% 33$ & $\mathrm{~V}$ \\
\hline لحمر & أليف صناعية & $r$. & $\mathrm{A} \% 50+\mathrm{F} \% 50$ & $\Lambda$ \\
\hline أبيض & غزل حلقي قطن & 14 & COTTON \%100 & 9 \\
\hline
\end{tabular}

\begin{tabular}{|c|c|c|c|c|c|c|}
\hline المسلمل & اللهن & أسلوب الغزل & $\begin{array}{c}\text { نمرة ناتج الزوى } \\
\text { Ne }\end{array}$ & النمر الفرية Ne & موالصفت الخيطا الفررة & العينة \\
\hline $0 * \varepsilon$ & تركوازلبيج & مبل كتلان & 0 & $17+V$ & $\begin{array}{l}(\mathrm{A} \% 60+\mathrm{F} \% 40) \\
(\mathrm{A} \% 60+\mathrm{F} \% 40) \\
\end{array}$ & 1 \\
\hline$q * \mu$ & بيج / أبيضض & قُّليف صناعية+ & $\mathrm{V}, 0$ & $r \cdot+1 r$ & $\begin{array}{r}(\mathrm{A} \% 100) \\
(\text { Cotton\%100) } \\
\end{array}$ & $r$ \\
\hline$\left.\Lambda^{*}\right\rceil$ & لحمر/ بيج & ألأليف صناعية & $\Lambda, 0$ & $r++10$ & $\begin{array}{l}(\mathrm{A} \% 50+\mathrm{F} \% 50) \\
(\mathrm{A} \% 50+\mathrm{F} \% 50) \\
\end{array}$ & $\mu$ \\
\hline $\mathrm{V} * \mathrm{r}$ & ل لحمر/ لحمر & ألئل صناعية & 9 & $r \cdot+17$ & $\begin{array}{l}(\mathrm{A} \% 67+\mathrm{P} \% 33) \\
(\mathrm{A} \% 67+\mathrm{P} \% 33) \\
\end{array}$ & $\varepsilon$ \\
\hline $7 * 1$ & رُصاصي/بيج & أْمُبل كتانِ صناعة & $1 \cdot, 0$ & $10+\mu \varepsilon$ & $\begin{array}{l}(\mathrm{A} \% 50+\mathrm{F} \% 50) \\
(\mathrm{A} \% 50+\mathrm{F} \% 50)\end{array}$ & 0 \\
\hline
\end{tabular}

جرل ب. الموالمفلت الفنية لمكينة الزوى الحلف

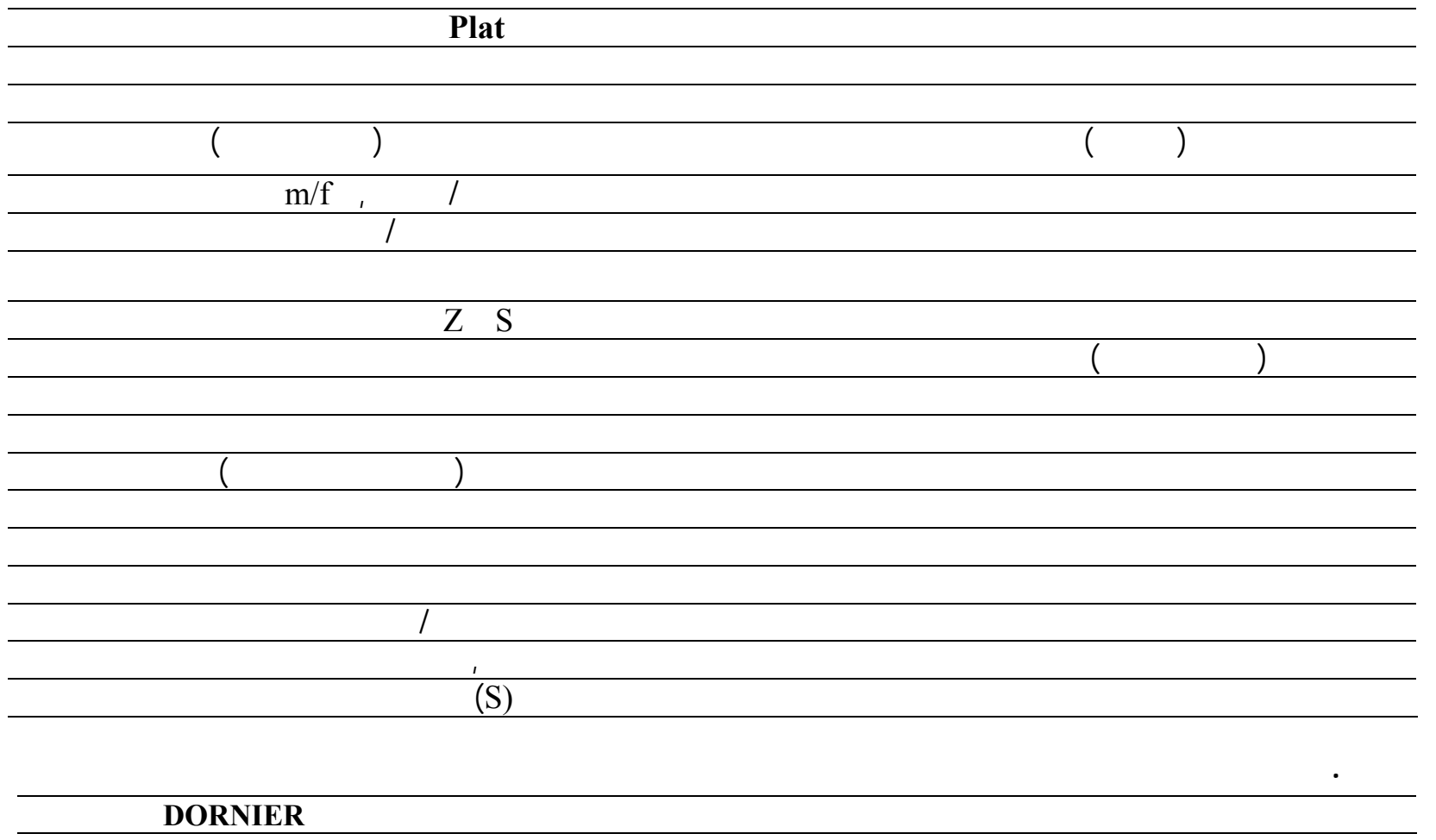




\begin{tabular}{|c|c|}
\hline GERMANY & 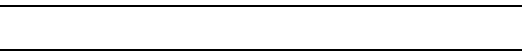 \\
\hline $19 \Lambda \mu$ & سنة الصنع \\
\hline الحربة الصلبة (رلبير) & طِريقة القذف لخبوط اللحمة \\
\hline aurr. & أقصص عرض للآقمشة المنتجة على النول \\
\hline مغذى كهربي Feeder accumulator & وحةة تغذنية اللحمة \\
\hline weft cellector 7 & وحلة تغيير اللحمة \\
\hline Staubli & نوع جهاز الدوبى \\
\hline 14 & قوة جهاز الدوبه \\
\hline موبج & الرخو \\
\hline موجب & الطي \\
\hline مبرد ا/" مبر & التركيب النسجي المستخهم \\
\hline 1 1بب لمبم & عدة المشط المستخدم \\
\hline ط طردي & نوع اللقى \\
\hline بـ فتلة في البب & الظريح \\
\hline buga & نوع الفس \\
\hline and 70 & عرض المسداء في المثط \\
\hline 11 & عدد الحدفت ليم \\
\hline$r \varepsilon$ & عدد خيوط للسداءلمم \\
\hline . & نمرة خيوط اللسداء \\
\hline • 0\%كريليك - - 0\%صوف(ازرق غلمق) & ئوع خيوط للسداء \\
\hline ELECTRONIC & لجهزة المراقبة لخيوط للسداء واللحمة \\
\hline
\end{tabular}

عينلت الففهة المنتجة

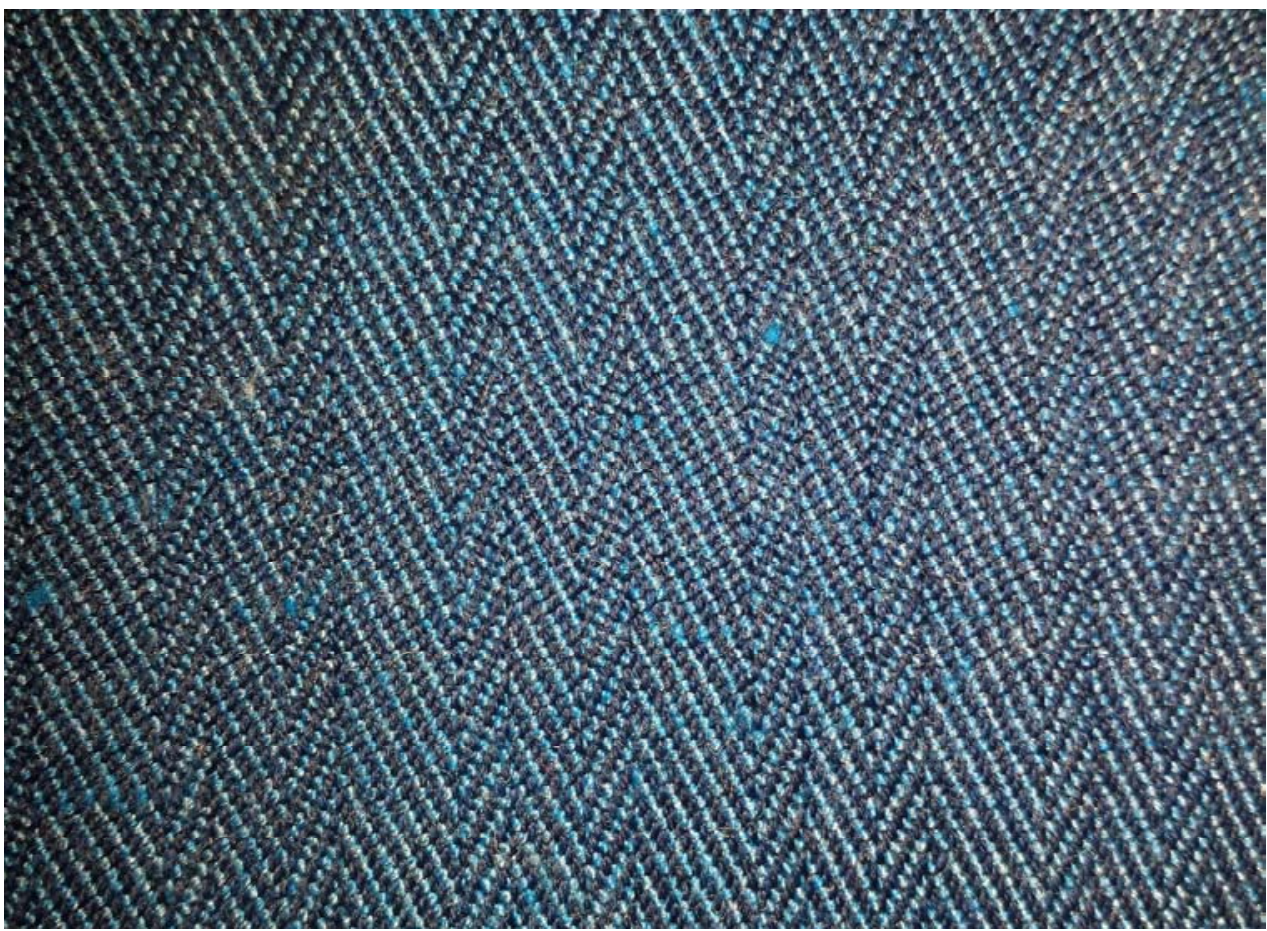

المينة I ـ ( • ד\% بولي كربليك+ • ع \% كتلن)

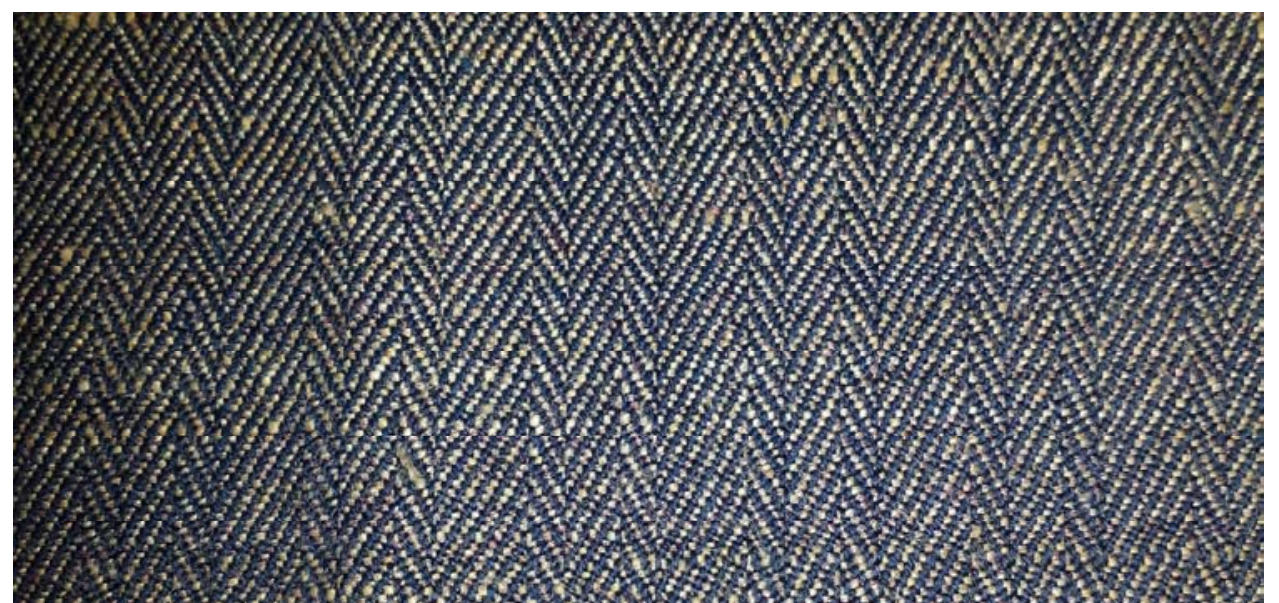


العينة r. ( . - ا\% بولي كربالك+ . - ا\%هنلن)

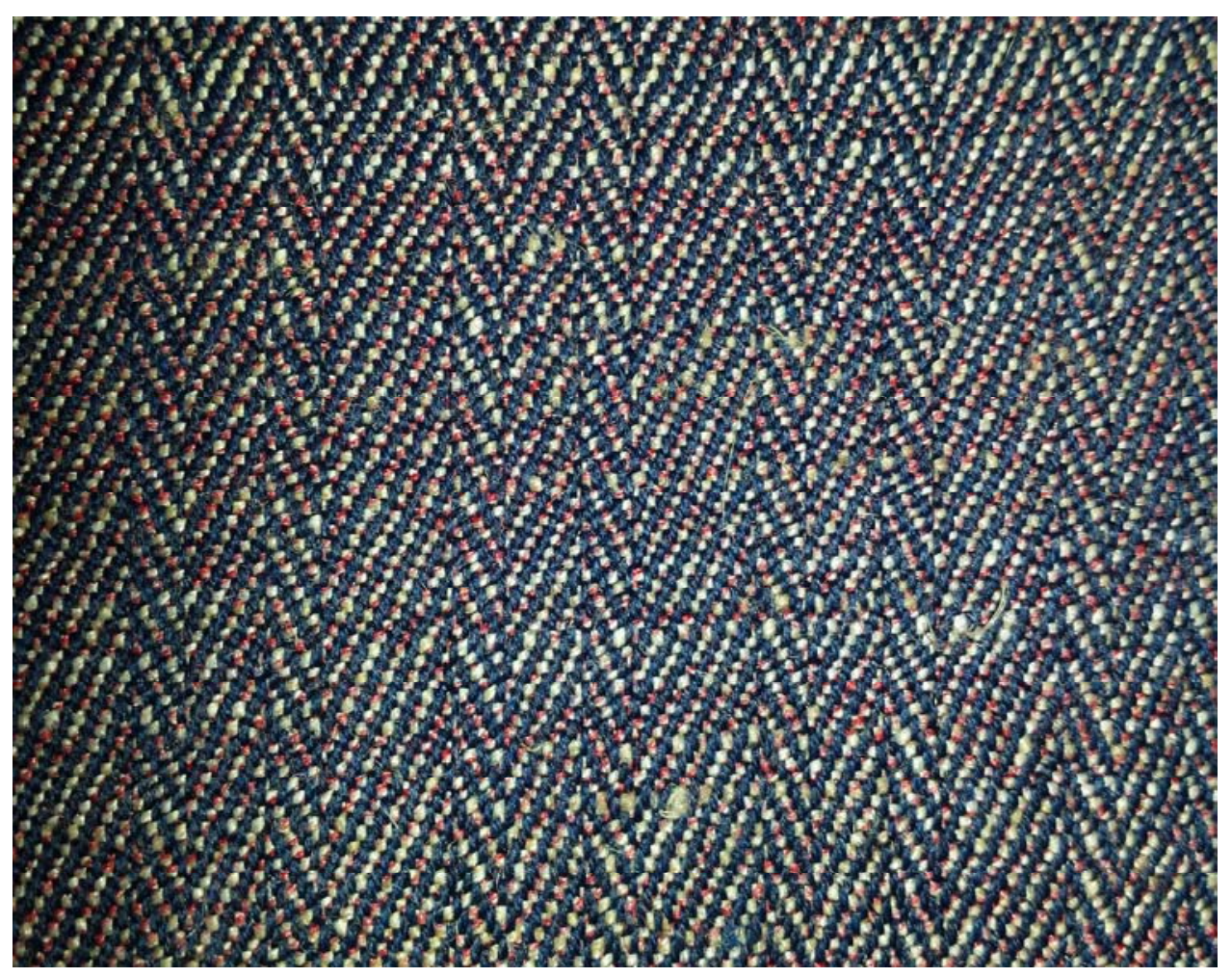

العينة r.( - 0\% بولي كريالك+ 0\%كنلن)

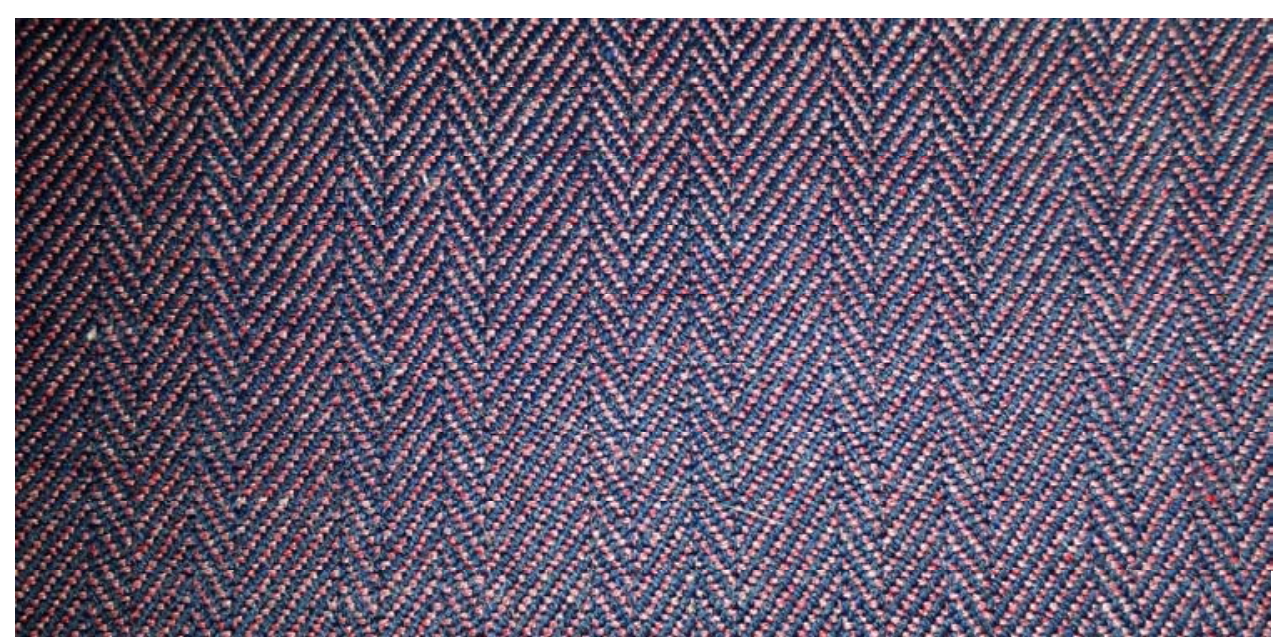




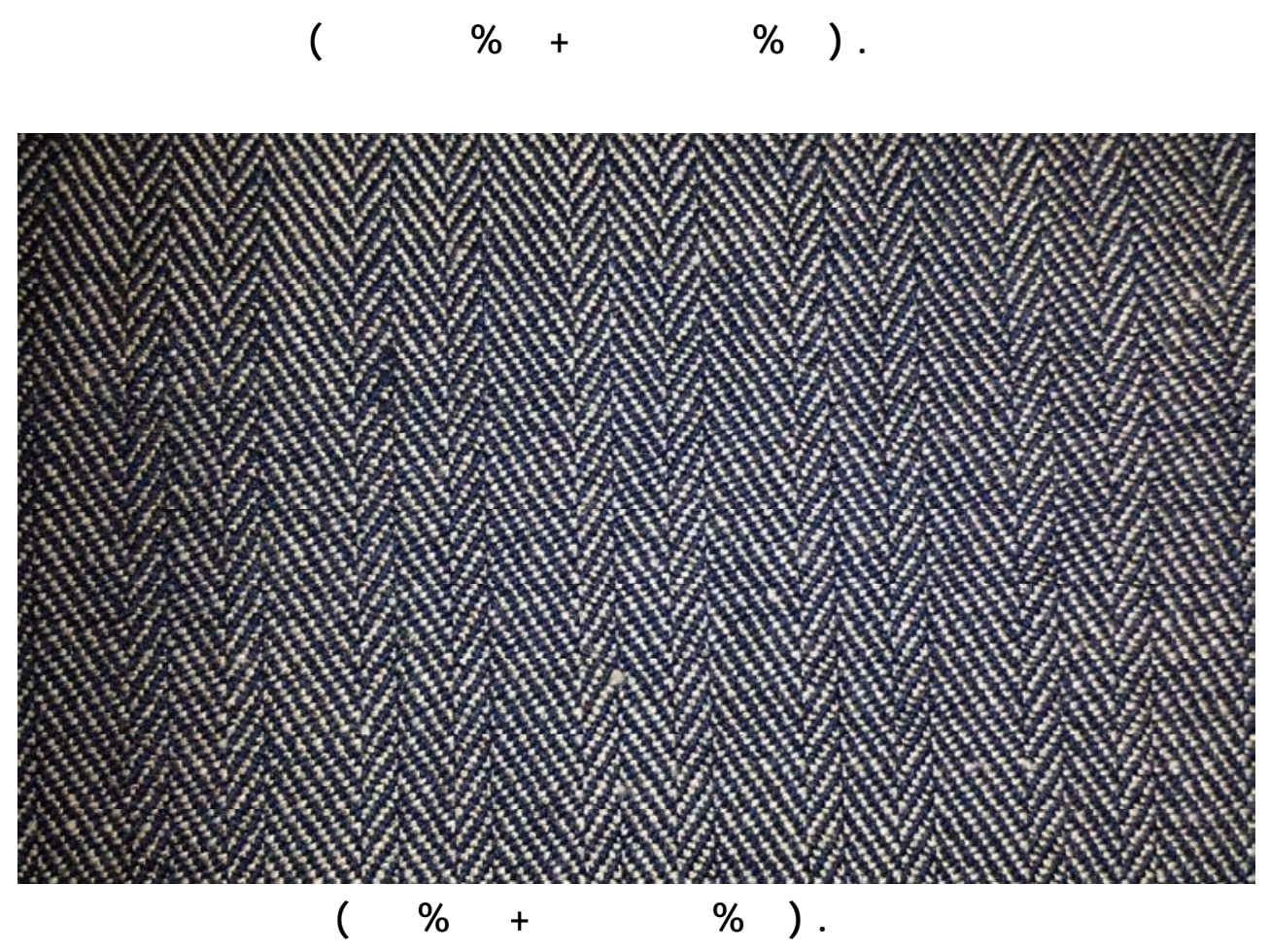

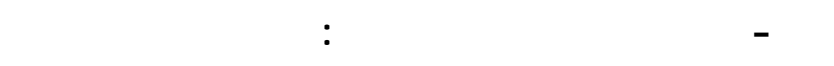

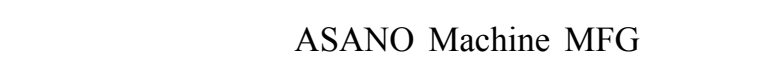
كنسبة منئوية(\%)طبا للمواصفلت القيلسية الأمريكي ـة .ASTM-D5035 ج -لختبار الفتدفي الونن للفٔفشة نتيجة لالحتك لك: ت م م

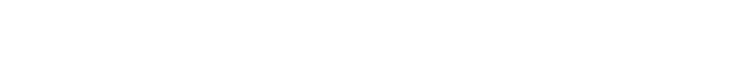
SEISAKU-SHO.LTEABRASIO INSTRUMENT D- مطقا للمواصفلت القيلسية الأمريكية،OYO SEIKI
في مَعلمل المركز القومي للبحوث بالدقي -القاهرة ووضعت

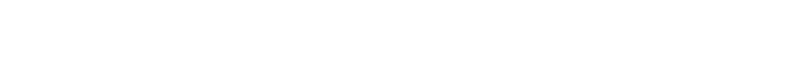

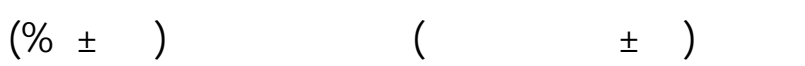
لمدة عruاعة قل إجراء الاختبارات عليها.

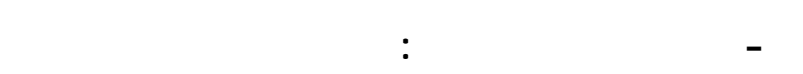

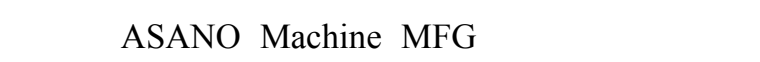
للمواصفت القيلسية الأمريكية ASTM-D5035. 
المحور الرالع: مدى تحقيق أقم شة الملاب س الخارجي ة للسيدات المنتجة للنلحية الوظيفية.

وقم قيلس كل عبارة عن طريق وضع مقيلس (منلسب، منلبب إلى حد ما، غير منلبب) حيث أعطيت للد تجابلت

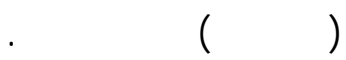
الصسق والثبلت لاستمارة قيم للسادة المحكمين: لأقم شة الملابس الخارجية للسيدات المنتج ـة م ن بـ -واقي خي -وط

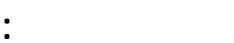

أولاً: لختبار صسق محتوي الاستمارة: للتهقق من ص حق

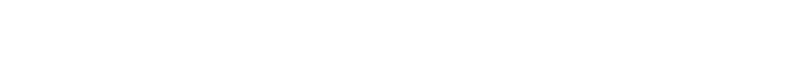

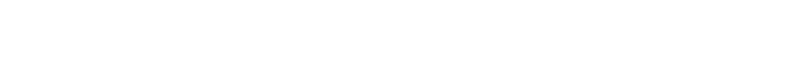
الاقتصاد المذزلي (تخصص ملابس ونسبج) وكلية الفن -ون بلهن

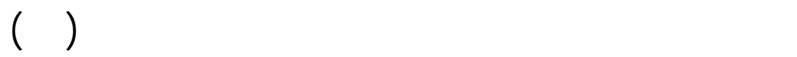
محكما. وق مسلب شنبة الانفق لدي المحكمين علي كل عبارة

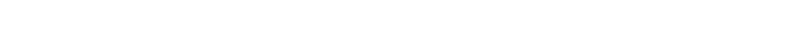

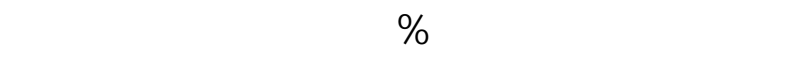
وبذك تكون الإنمارة قد خضعت لصدق المحتوي. ثانياً: لختبار شبك الاستمارة: لمسلب ثبلت الاستمارة تم م الظبيق على عينة قولمها (0) تصميملت تتوافر فيها فـ سبات شروط عينة الدرلسة وبعد الظبق مت هسلب الثبلت بطريقة

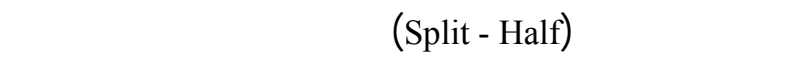

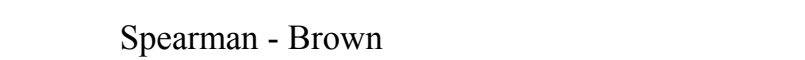
الارتبط بين نصفي كل محور من محاور الاستمارة. ويوضح الجدول رقم(0) أن معلم لـ ارتب لـا لـ التجزئ ــة النصفية للمستبيلن لسبيرملن- براون معلملات مقبولة نسبياً وتأسيسا على ماسبق أصسح الإستبيلن في صورته النهائي ـة يتكون من · r عبارة مقنمة إلى ع محاور.

جطل 0.معالل الرتبلا الجزئة النمفية لمح الور الاس تمارة

\begin{tabular}{|c|c|}
\hline معالل الرتبلالسبيرملن - مبراهن & المحور \\
\hline$\cdot, q \mu$ & مدي تهقيق عناصر التصميم \\
\hline
\end{tabular}

ASTM- 1175

.PS5690 د -لختبار صطلبة الفهشة: مُ إجراء هـ ـذا الاختب ار عل م.

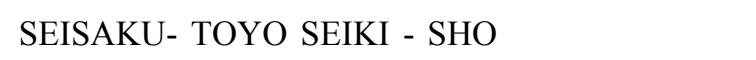
وفقا للمواصفلت القيلسية الأمريكي ـة والمواصفة القيلسية البريطانية BS3356. ه -لختبار مقاومة الأفهة لالتمزق: م إجراء هذا الاختب ار

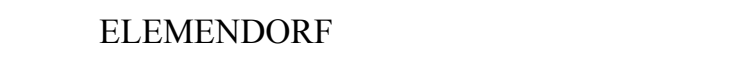
للمواص ـفلت القيلس ـية الأمريكي ــة ASTM-D1424 . ASTM-D22619

و - لختبار ونن المتر المرع للأفهشة: ت م إج ـراء هـ ذذا

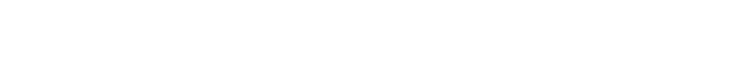
SARTARIUS ELECTRONIC BALANCE الصنع ذو مسلسية حتى ا .., جرالم وفقا للمواصفلت القيلسية الأمريكية ASTM-D3776.

r - صممت لستمارة لستبيلن وعرضت على مجموعة( · r) من المتخصصين في مجل الملابس والمنسوجلت بقم الغزل والنسبج والتريكو بكلية الفنون الظبيقية- جلمعة فملفي حلوان وقسم الملابس والنسبج بكلية الاقتصاد المذزلي-

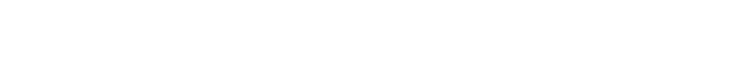

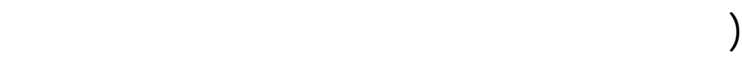

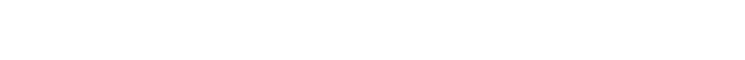

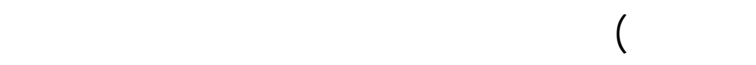
محور يضم مجموعة من البنود: المحور الأول:مدى تحقيق أقم ششة الملاب س الخارجي ـة للسيدات المنتجة لعناصر التصميم. المحور الثاني:مدى تحقيق أقم ششة الملاب س الخارجي ـة للسيدات المنتجة للأسس التصميم. المحور الثالث:مدى تتقيق أقم شة الملاب س الخارجي ـة للسيدات المنتجة للنلحية الجمالية. 
من فروض البهث والذي ينص علي "تمقق أقمشة الملابس

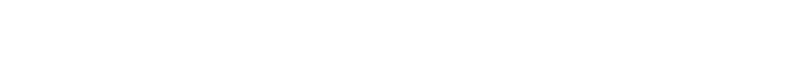

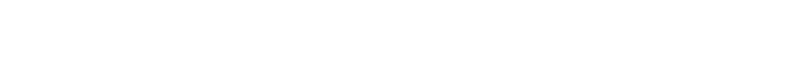

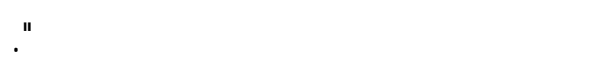

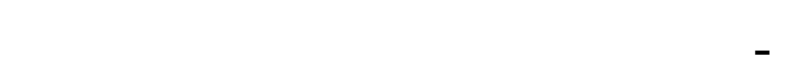

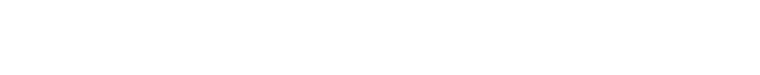
ألس التصميم:

الفرض الثالي: (تحقق أقمشة الملابس الخارجية للا سيدات

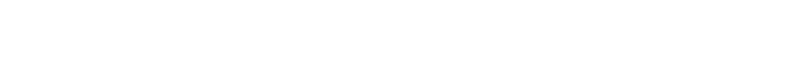

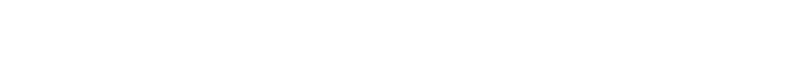
من محاور القيم وهو لمنس تصنميم). تشنير نتائج جدول (V) إلي أن أقمشة الملابس الخارجية

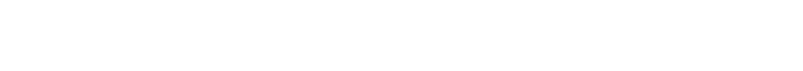

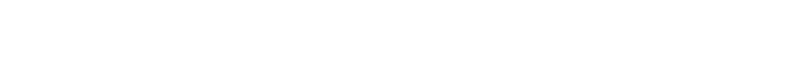

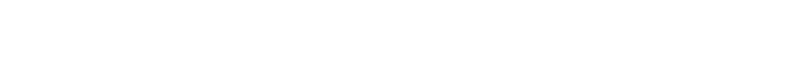

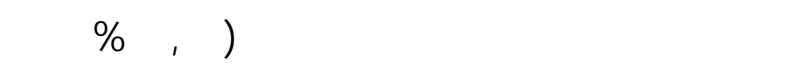

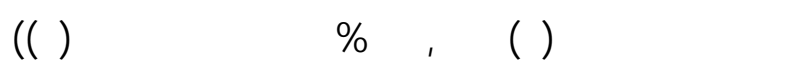

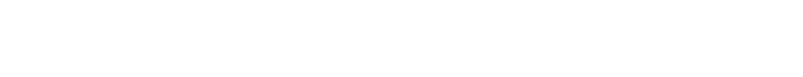

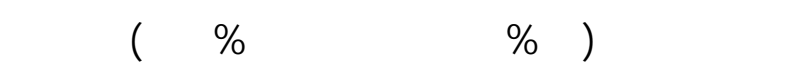

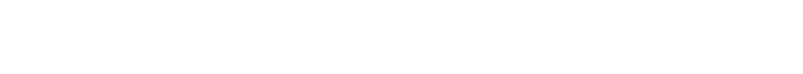

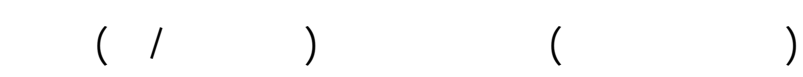

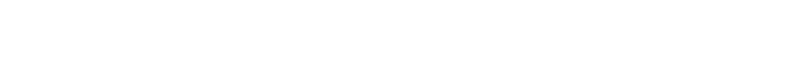

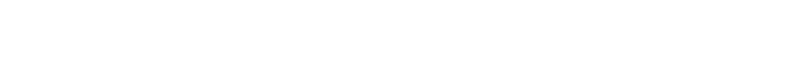

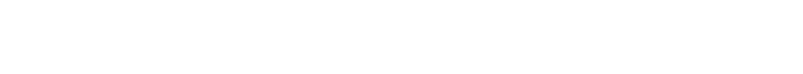

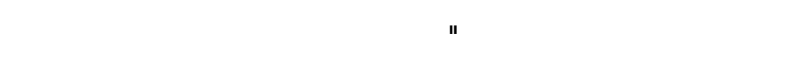

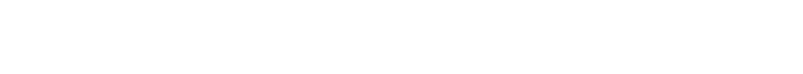

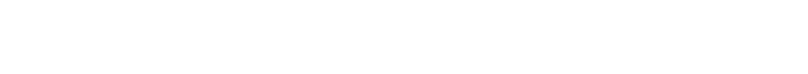
الثالي من محاور القيم."

r - محور المدك نجاح لفمشة الملابس الخارجية لل عسيدلت

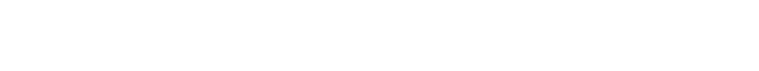

النالحية الجمالية:

\begin{tabular}{rr}
\hline الأسلوب الإلجمالي \\
\hline الإئي:
\end{tabular}

لمستخمت المتوسطلت والانحرافلت المعيارية وتحلي لل

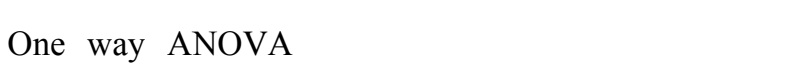

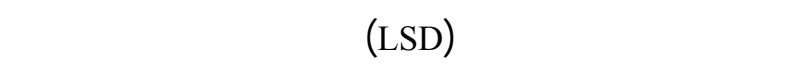
ومعلمل الارتبطا لسبيرمان (ع).

\section{النتائج ومنالثشتها}

أولا: نتنائج البهث في ضوء قييملت المكمبن: 1 - محور محك نجاح أفمشة الملابس الخارجية للاعسيدل

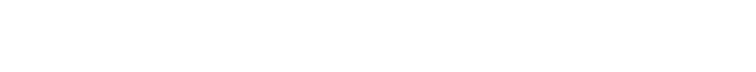
عنامر التصميم:

الفرض الأطل: (تحقق أقمشة الملابس الخارجي ـة للا سيدات

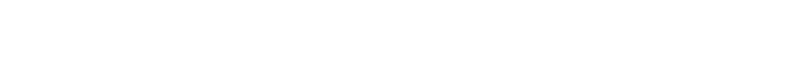

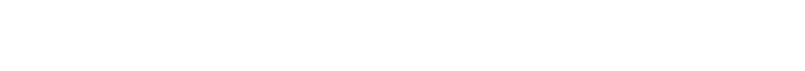
من محاور القيم وهو عناصر التصميم).

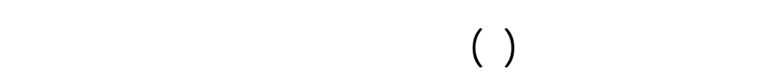

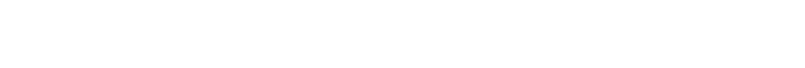

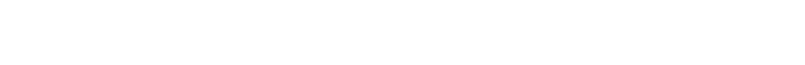

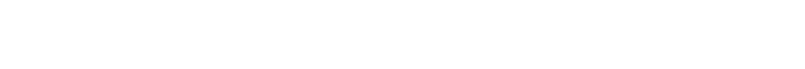

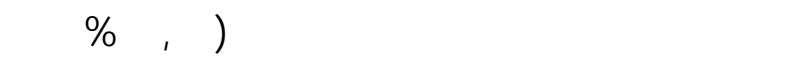

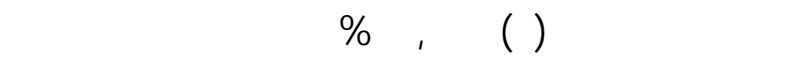

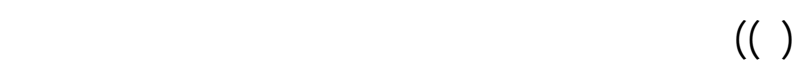

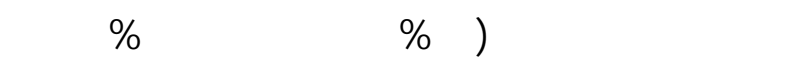

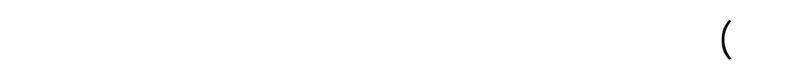

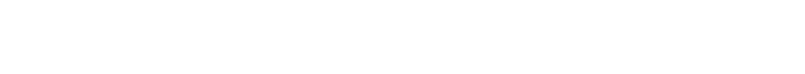

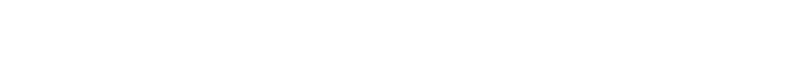

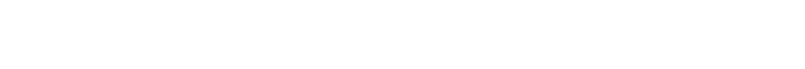

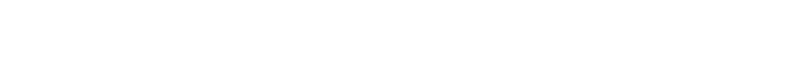

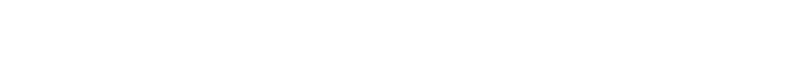


الرابعة والمصنوعة من(7V\% بولي لكريليك، سب\%\%ب -ولي

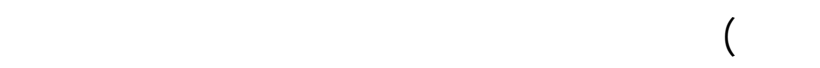

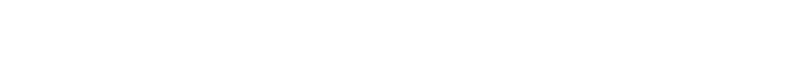

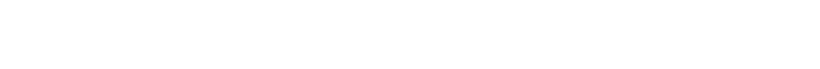

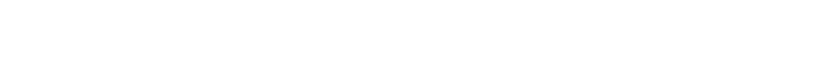

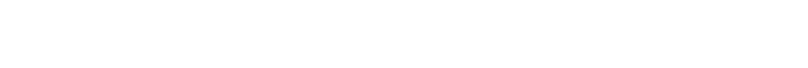

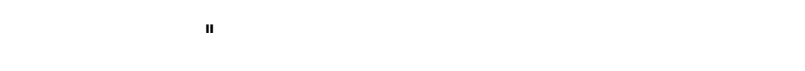

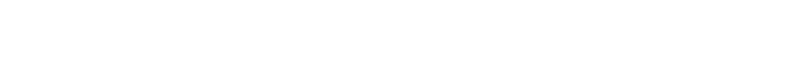

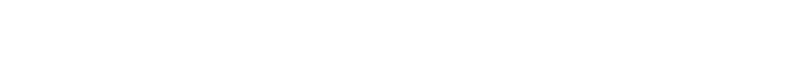

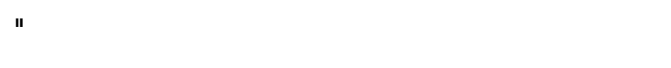

الفرض الثالث: (تحقق أقمشة الملابس الخارجية للا سيدات

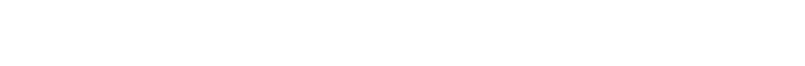

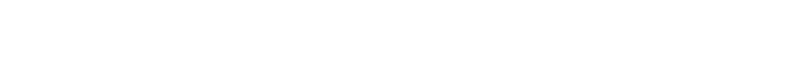
من محاور القيم وهو الناحية الجمالية) تشير نتائج جدول (^) إلي أن أقمشة الملابس الخارجية للسيدات المتتجة من بوالقي خيوط الخاله لـ الت المختلف ـة ق و 2

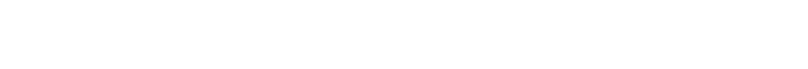

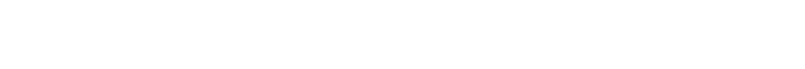

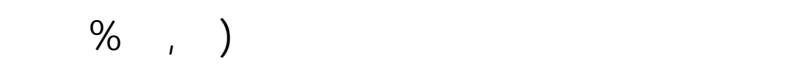

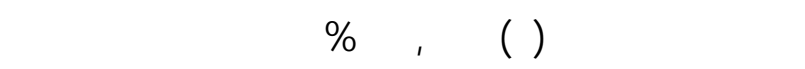

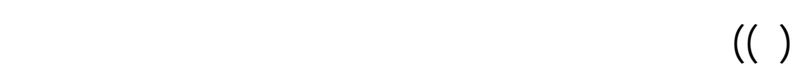

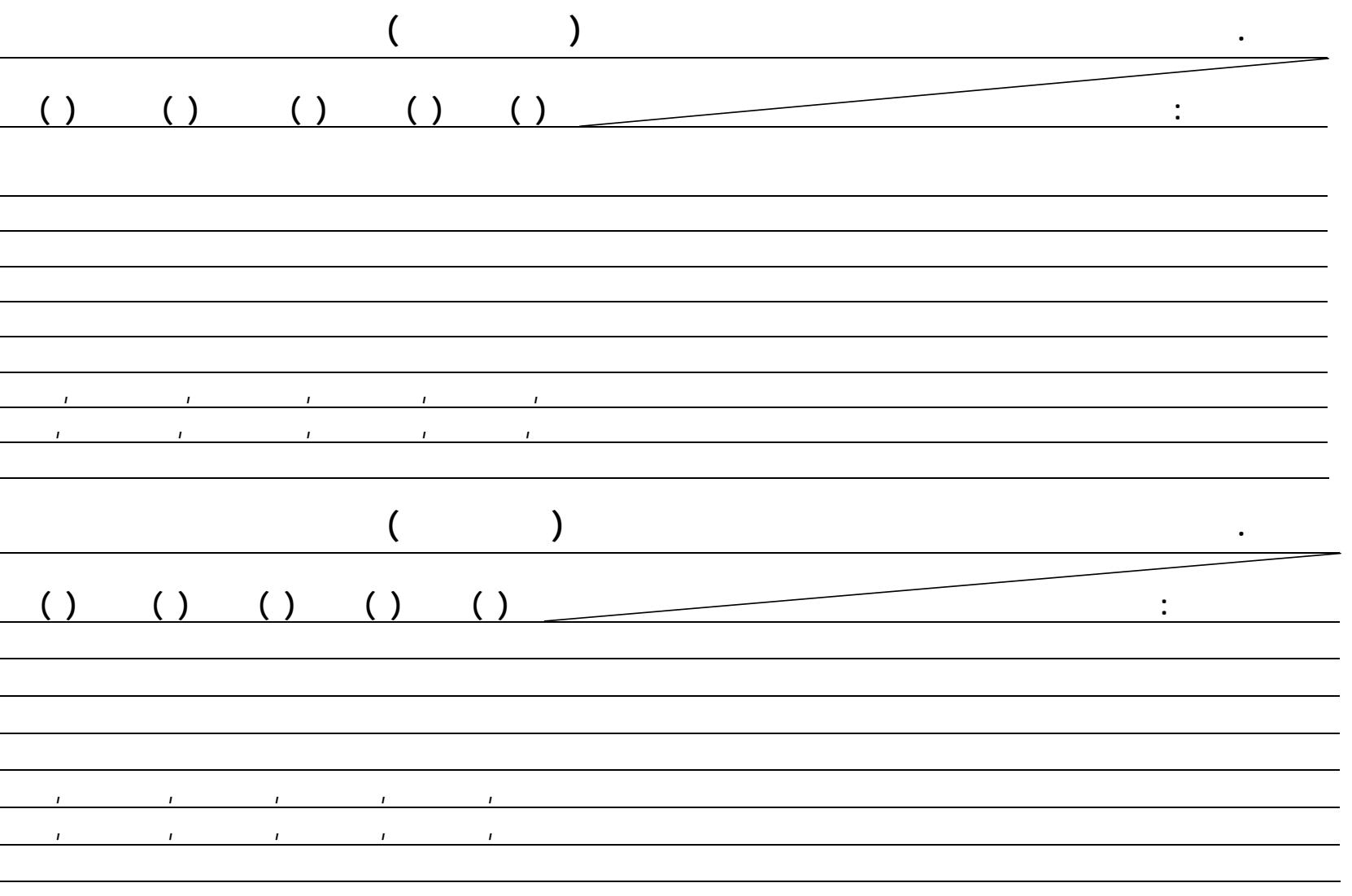

جدط ^.متومطلت قييم المحكمن لمحور الثالثمنمحاور القيم( الناحية الجمالية)

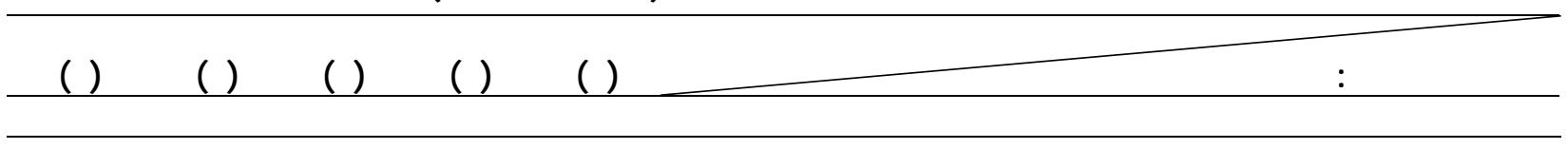




\begin{tabular}{|c|c|c|c|c|c|}
\hline 09 & OV & 09 & $0 \Lambda$ & 09 & تاثير كثلفة القملث على الهظهر الجمالي \\
\hline $0 \Lambda$ & 09 & 07 & OV & 09 & مدى النجاح في تولف الخلملت من حيث الملهر \\
\hline OV & 09 & OV & 07 & $0 \Lambda$ & قدرة التركيب النسجي وألوان الخيوط على إضفافة نولحي جمالية للملبس \\
\hline OV & $0 \Lambda$ & 09 & OV & OV & الخلمة تعتبر من الأفمشة الزخرفية \\
\hline $1 \varepsilon, 0 \cdot$ & $1 \varepsilon, 00$ & $\mid \varepsilon, \varepsilon \cdot$ & $1 \varepsilon, r 0$ & $\mid \varepsilon, 0$. & متوط ققيملت المحكمين \\
\hline $97,7 V$ & $9 \mathrm{~V}, \cdot \cdot$ & $97, \cdot \cdot$ & $90,7 \mathrm{~V}$ & $97,7 \mathrm{~V}$ & تقيم الجودة الكلية للمحور \\
\hline$r$ & 1 & $\varepsilon$ & 0 & $\mu$ & ترتيب العينات في ضوء ققيم الجوة للمحور \\
\hline
\end{tabular}

الفرض الخالس: (تهقق أقمشة الملابس الخارجية للسيدات

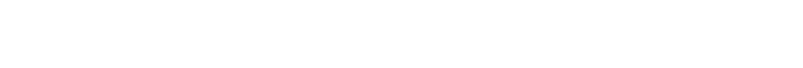
ونجاح في ضوء متوسطلت نقيم المحكمين لمحاور القيم المختيم (الإجمالي)(احن). - نشير نتائج جدول ( · ( ) إلي أن أقمشة الملابس الخارجية للسيدات المنتجة من بواقي خيوط الخلملت المختلفة ق ــ جمقت درجة قبول ونجاح في ضوء متوس طلت نقي يم المحكمين لمحاور القيم(الإجمالي) حيث تراوح نقي يه فيم

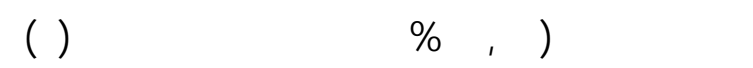

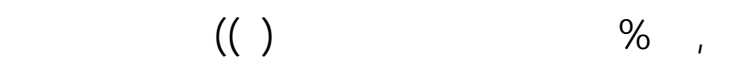

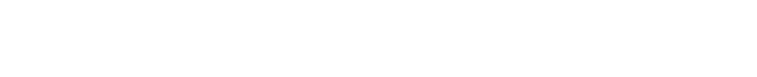

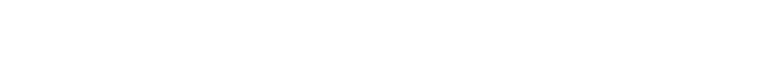

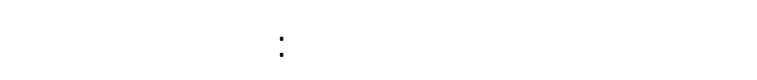

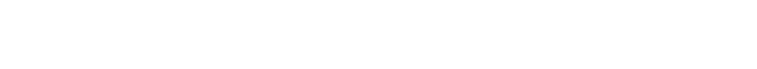

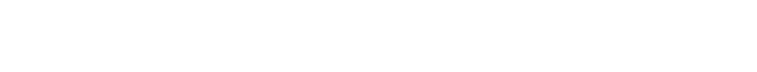

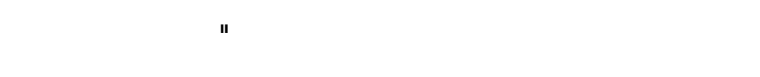

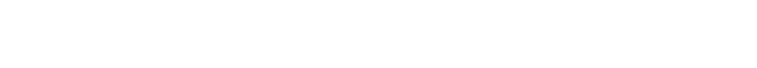

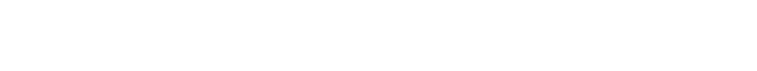
متوسطلت ققيم المحكمين لمحاور القيم(الإجمالي). الغرض الساس:(يوجد فرق دل إحصائيا عن ـد مـ ستوي 0 • , . بين متوسطلت محاور نقيم أقمشة الملابس الخارجية

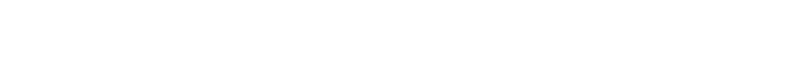
ضوء قييمك المحكمين).

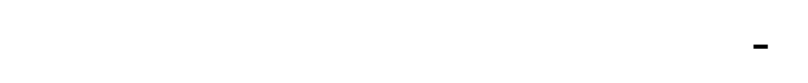

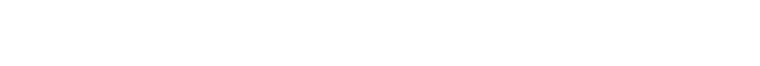

\section{الناحية الظلفية:}

الفرض الرالع: (تحقق أقمشة المالابس الخارجية لل سيدات

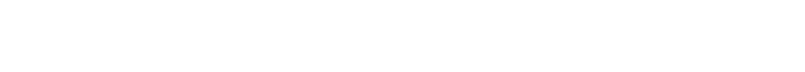

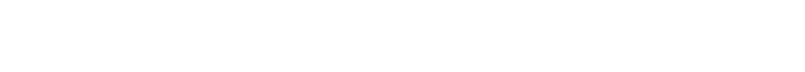
من محاور القيم وهو النلحية الوظيفية). تشير نتائج جدول (9) إلي أن أقمشة الملابس الخارجية للسيدات المنتجة من بواقي خيوط الخلملت المختلفة حقق ت

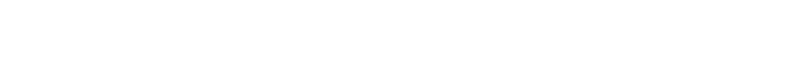
للمحور الراليع من محاور القيم وهو النلحية الظفية فية حيث

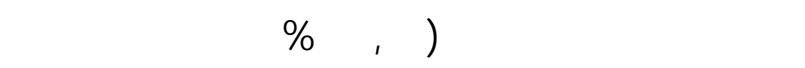

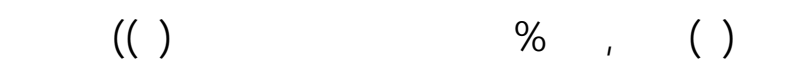

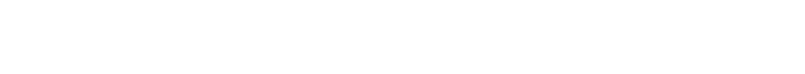

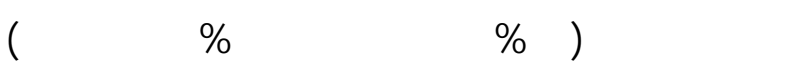
لأنها ذات درجة لمعلن ونعومة محببة وك ذالك الن سداليتها

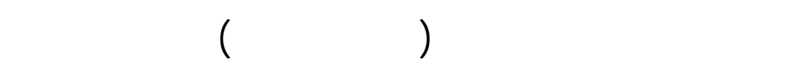

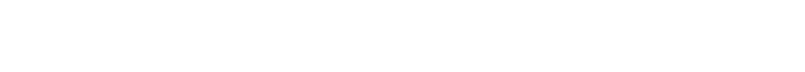

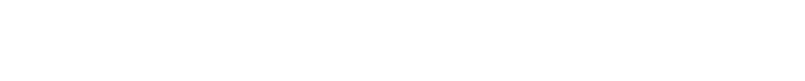

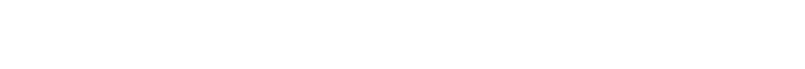

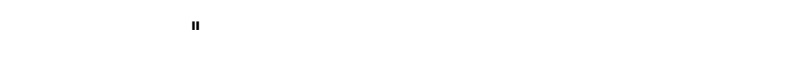

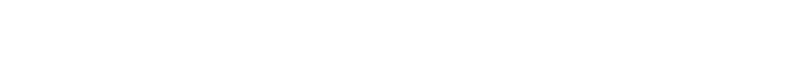

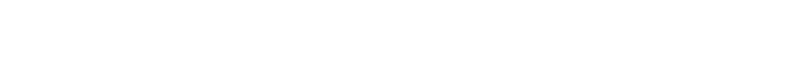

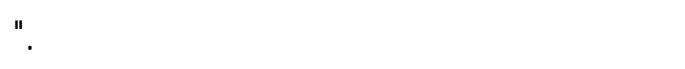

0 -محاور القيم (الإجمالي) للعينلت المنتجة:

جدط 9.متومطلت فييملت المحمين المحور الرلع من محاور القيم (الناحية الولفية)

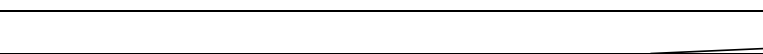




\begin{tabular}{|c|c|c|c|c|c|}
\hline (0) & (ع) & (ए) & (T) & (1) & المحور الرلع:مدى نحقيق الناحية الولفية \\
\hline 09 & $0 \Lambda$ & 09 & OV & $0 \Lambda$ & درجة اللمعلن للقملثش \\
\hline $\mathrm{OV}$ & 09 & 01 & 09 & OV & لنسدالة القملثر \\
\hline 09 & $0 \wedge$ & $0 \wedge$ & 07 & $0 \Lambda$ & مقاومة القملث للاتساخ \\
\hline $0 \Lambda$ & 09 & 07 & 01 & 09 & تأثير النعومة على الآداء الوظيفي \\
\hline 09 & $0 \Lambda$ & 09 & $\mathrm{OV}$ & 01 & العينة المففة تلب حلجة السيدات \\
\hline $\mid \varepsilon, 7$. & $\mid \varepsilon, 7$. & $\mid \varepsilon, 0$. & $I \varepsilon, \mu O$ & $\mid \varepsilon, 0$. & متوط ققيمات المحكمين \\
\hline$Q V, \mu \mu$ & QV, ${ }^{\mu} \mu$ & $97,7 \mathrm{~V}$ & $90,7 \mathrm{~V}$ & $97,7 \mathrm{~V}$ & ققيم الجودة لققيمات المحكمين \\
\hline$r$ & 1 & $\varepsilon$ & 0 & $\mu$ & الترتيب \\
\hline
\end{tabular}

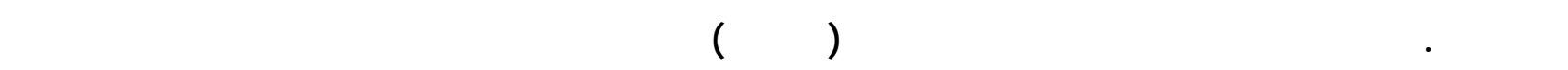

خيط الخاملت المختلفة

\begin{tabular}{|c|c|c|c|c|c|c|c|c|c|c|c|}
\hline \multirow[b]{2}{*}{ الترتيب } & \multirow[b]{2}{*}{ الجويمة } & الإجمالي & \multicolumn{2}{|c|}{ الناحية الولفية } & \multicolumn{2}{|c|}{ الناحية الجمالية } & \multicolumn{2}{|c|}{ لمسب التصميم } & \multicolumn{2}{|c|}{ عناهر التصميم } & \multirow[b]{2}{*}{ العينات } \\
\hline & & المتوجملتل & الجويمة & المتوطbا & الجيمة & المتوطbا & الجويمة & المتوطما & الجويمة & المتوطما & \\
\hline$\mu$ & $97, \Lambda \mu$ & $0 \wedge, 1$ & $97,7 V$ & $\mid \varepsilon, 0$. & $97,7 V$ & $1 \varepsilon, 0$. & $97,7 V$ & $11,7$. & 9V,r & IV,0. & 1 \\
\hline 0 & $90, \wedge \mu$ & $O V, O$. & $90,7 \mathrm{~V}$ & IE, & $90,7 \mathrm{~V}$ & IE, & 97, ҮO & 11,00 & $90, \wedge \mu$ & IV,YO & $r$ \\
\hline$\varepsilon$ & $97,0 \wedge$ & OV, १० & $97,7 \vee$ & $\mid \varepsilon, 0$. & $97, \cdots$ & $\mid \varepsilon, \varepsilon$. & $97,7 \vee$ & $11,7$. & ૧७,१६ & $\mid \mathrm{V}, \varepsilon 0$ & $\mu$ \\
\hline 1 & QV,Eर & $0 \wedge, \varepsilon 0$ & QV, & $\mid \varepsilon, 7$. & १V, . & $1 \varepsilon, 00$ & १७, 0 . & $11, \mathrm{~V}$. & १V,V^ & $18,7$. & $\varepsilon$ \\
\hline$r$ & QV,ro & $0 \Lambda, \mathrm{r}^{\mathrm{N}} \mathrm{O}$ & QV,ru & $1 \varepsilon, 7$. & $97,7 V$ & $1 \varepsilon, 0$. & $9 V, 94$ & $11, \mathrm{~V} 0$ & QV,rY & $1 \mathrm{~V}, 0$. & 0 \\
\hline
\end{tabular}

الجمالية، النلحية الوظيفية) حيث الفروق بين المتوسطنت دالة عند مستوي 0 ., . .

r - توجد فروق بين متوسطلت محور "لأسس التصميم وكل

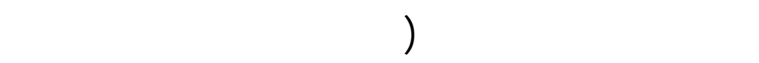
الوظيفية) حيث الفروق بين المتوسطلت دالة إحصائياً. ويمكن ترتيب المحاور ف مي ض -وء متوس طلت ققيم لت

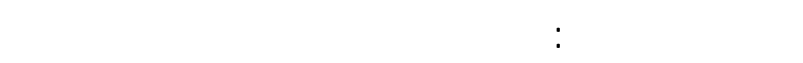
النلحية الجمالية، لأسس التصميم.

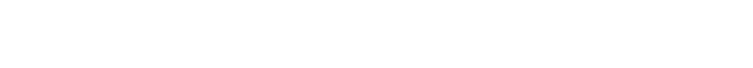
الساس من فروض البحث والذي ينص علي " يوجد ف ـرق فئي

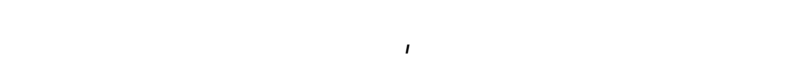
أقمشة الملابس الخارجية للسيدات المنتجة من بواقي خيوط الخلملت المختلفة في ضوء ققيمكت المحكمين.
وللتمقق من صحة هذا الفرض مُ عسلب تحلي لل التب اين

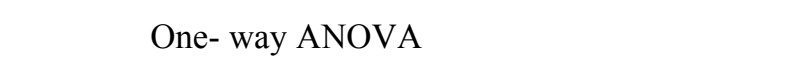
المحكمين لأقمشة الملابس الخارجية للسيدات المنتجة مـ بواقي خيوط الخلملت المختلفة في ضوء محاور القيم كما هوموضح بجدول (11). يتضح من الجدول وجود فرق دل إحصائيا عند مستوي

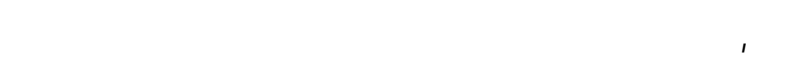

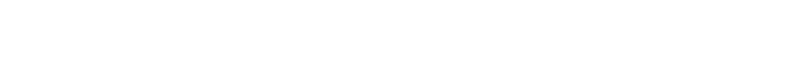

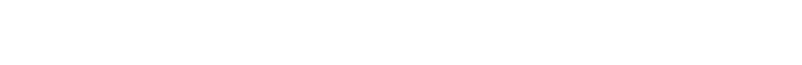
"ف" ع7, rVVI وهي دالة إحصائيا. ولتلكيد دلالة الفروق بين محاور القيم م ظبيق لختبار LSD

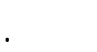
يتبين من النتائج التي يلخصها جدول (r I) أنه: 1 - توجد فروق بين متوسطلت محور "عناص ـر الت صميم

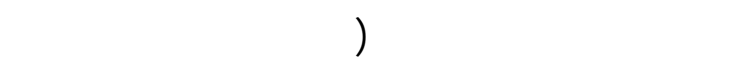

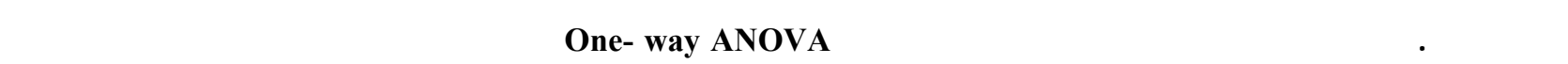

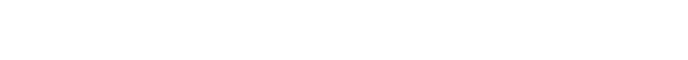




\begin{tabular}{|c|c|c|c|c|c|}
\hline مستوي الدلالة & قيمة "لى" & متوطb المرaكت & درجلت الحربة & مجموع المرحكت & مصرر التبلين \\
\hline \multirow{3}{*}{$\cdot, \cdots$} & \multirow{3}{*}{ rVVI, ש } & $r \Lambda, r \mu\urcorner$ & $\mu$ & $\Lambda \varepsilon, \vee \cdot \Lambda$ & التباين بين المجموعلت \\
\hline & & $\cdot, \cdot 1$. & 17 & $\cdot, 17 \mu^{\mu}$ & التباين دلخل المجموعلت \\
\hline & & & 19 & $\Lambda \varepsilon, \wedge \vee ।$ & التباين الكلي \\
\hline
\end{tabular}

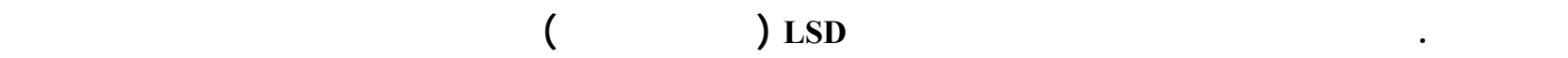

\begin{tabular}{|c|c|c|c|c|}
\hline & & & & ضوء ققييمك المككمن \\
\hline م= الناحية الولفية & 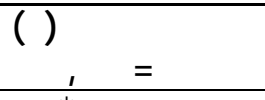 & 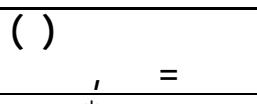 & 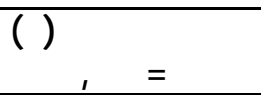 & \\
\hline$* r, 90$ & $* \mu, \cdots$ & $* 0, \wedge r$ & & عناصر التصميم (1) \\
\hline$* r, \Lambda V$ & $* r, \Lambda r$ & & & 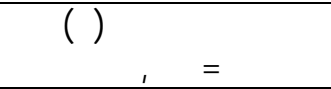 \\
\hline$\cdot .0$ & & & & 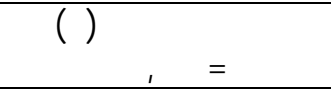 \\
\hline & & & & 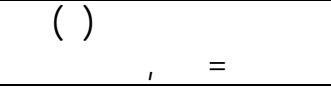 \\
\hline
\end{tabular}

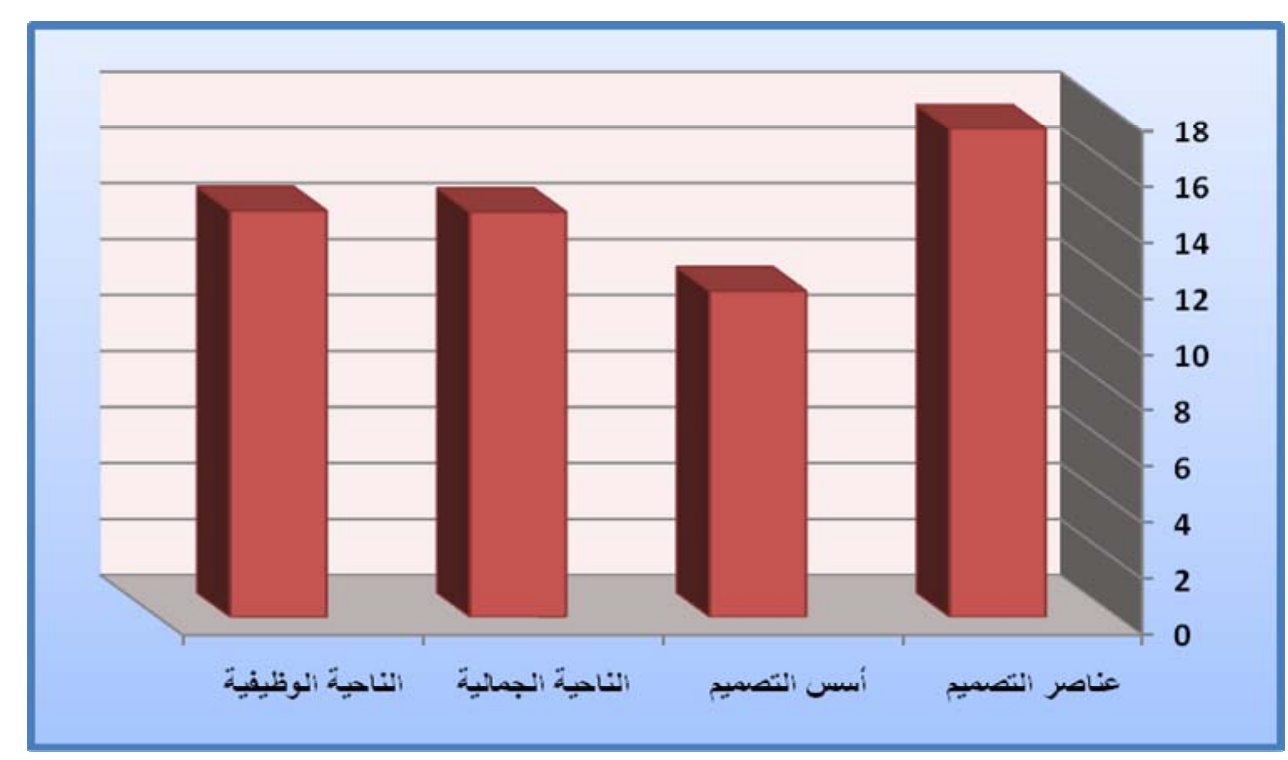

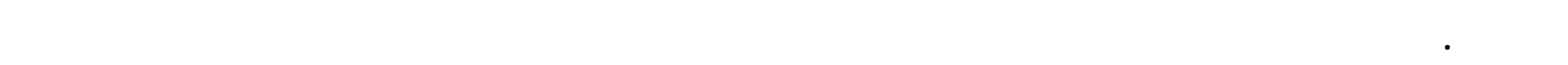

\section{ضوءمحاور القيم(الإجمالي)}

للسيدات المنتجة من بواقي خيوط الخلملت المختلفة كما هو

موضح بجدول (1) (1).

يتضح من الجدول عنم وجود فرق دل إحصائيا عن ــ

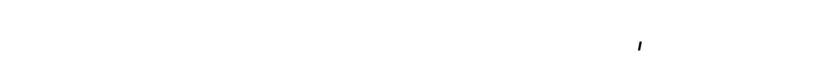

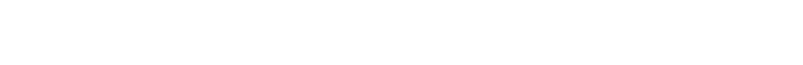

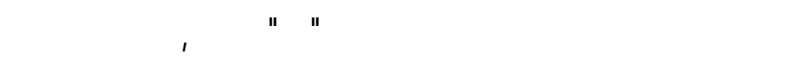
دالة إحصائيا ويمكن ترتيب أقم شئة الملاب س الخارجي فة فيمة
الفرض السليع: (يوجد فرق دل إح ـصائيا عذ ـدم ستوي 0 • , · بين متوسطك تقي سيم أقم ششة الملاب س الخارجي ـة

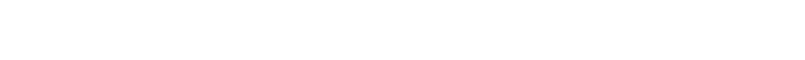

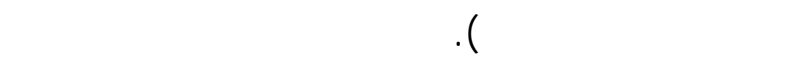

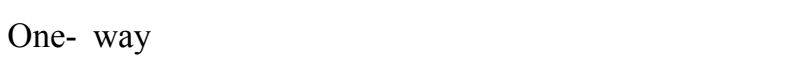
ANOVA لقييملت المحكمين لأقمشة الملاب س الخارجي ـة فيبرة 
الملابس الخارجية للسيدات المنتج ة مـ ن ب. -واقي خي -وط

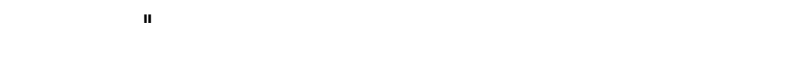
الفرض البيل والذي ينص علي لا يوجد فرق دل إحصائيا

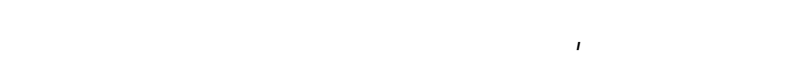

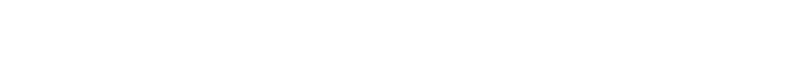
المختلة في ضوء ققييمات المحكمين.
للسيدات المنتجة من بواقي خيوط الخامك المختلف فة ف ي ضوء متوبطلت ققييمات المحكمن كما هو موضضح بجدئل وفي ضوء ماسبق من نتائج يمكن رف ـض الف -رض

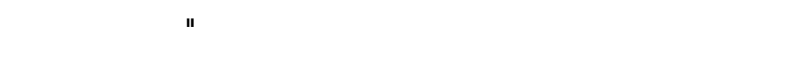

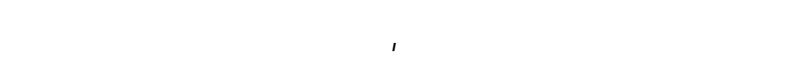

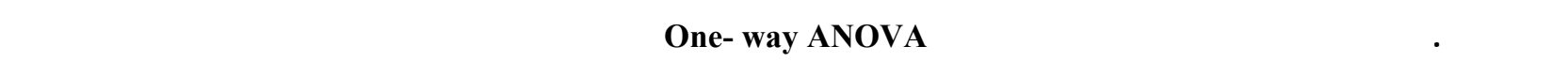
للسيدال المنتجة من بولف خيولا الخاملت المختلفة

\begin{tabular}{|c|c|c|c|c|c|}
\hline ـ مستوي الدעلة & قيمة'لف" & متوسط المربعلت & رججت الحربة & مجموع المرعات & مصرر التبلين \\
\hline \multirow[t]{3}{*}{$1, \cdots$} & $\cdot, \cdots 7$ & $\cdot, \cdot \mathrm{\mu O}$ & $\varepsilon$ & $\cdot,|\varepsilon|$ & التباين بين المجموعك \\
\hline & & $0,7 \varepsilon १$ & 10 & $\Lambda \varepsilon, V^{\mu} \mid$ & التباين دلخل المجموعك \\
\hline & & & 19 & $\Lambda \varepsilon, \Lambda \vee ।$ & التباين الكلي \\
\hline
\end{tabular}

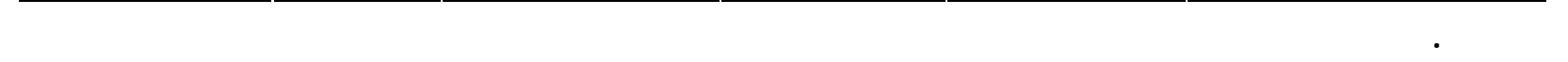

\begin{tabular}{|c|c|c|c|c|c|c|}
\hline الترتيب & الإجمالب & الناحية الولفية & الناحية الجمالية & ألس التصميم & عناهر التصميم & العينلك \\
\hline$\mu$ & $97, \wedge \Lambda^{\mu}$ & $97,7 \mathrm{~V}$ & $97,7 \mathrm{~V}$ & $97,7 V$ & $9 \mathrm{~V}, \mathrm{Yr}$ & 1 \\
\hline 0 & $90, \wedge \mu$ & $90,7 \mathrm{~V}$ & $90,7 \mathrm{~V}$ & $97, \mathrm{ro}$ & $90, \wedge \mu$ & $r$ \\
\hline$\varepsilon$ & 97,01 & $97,7 V$ & $97, \cdots$ & $97,7 V$ & $97,9 \varepsilon$ & $\mu$ \\
\hline 1 & $9 \mathrm{QV}, \varepsilon \mathrm{r}$ & $9 V,{ }^{\mu \mu}{ }^{\mu}$ & $9 \mathrm{~V}, \cdot \cdot$ & $9 \mathrm{~V}, 0$. & $9 \mathrm{~V}, \mathrm{~V} \wedge$ & $\varepsilon$ \\
\hline$r$ & $9 \mathrm{QV,YO}$ & $9 \mathrm{QV}, \mathrm{Y \mu}^{\mu}$ & $97,7 V$ & $9 \mathrm{9V}, 9 \mathrm{r}$ & $9 V, Y \mu$ & 0 \\
\hline النرتيب & معاللل الجوة & & 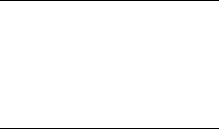 & & & العينت \\
\hline$\mu$ & $97, \wedge \mu$ & & $\begin{array}{r}97.4 \\
97.2 \\
97\end{array}$ & & & 1 \\
\hline
\end{tabular}




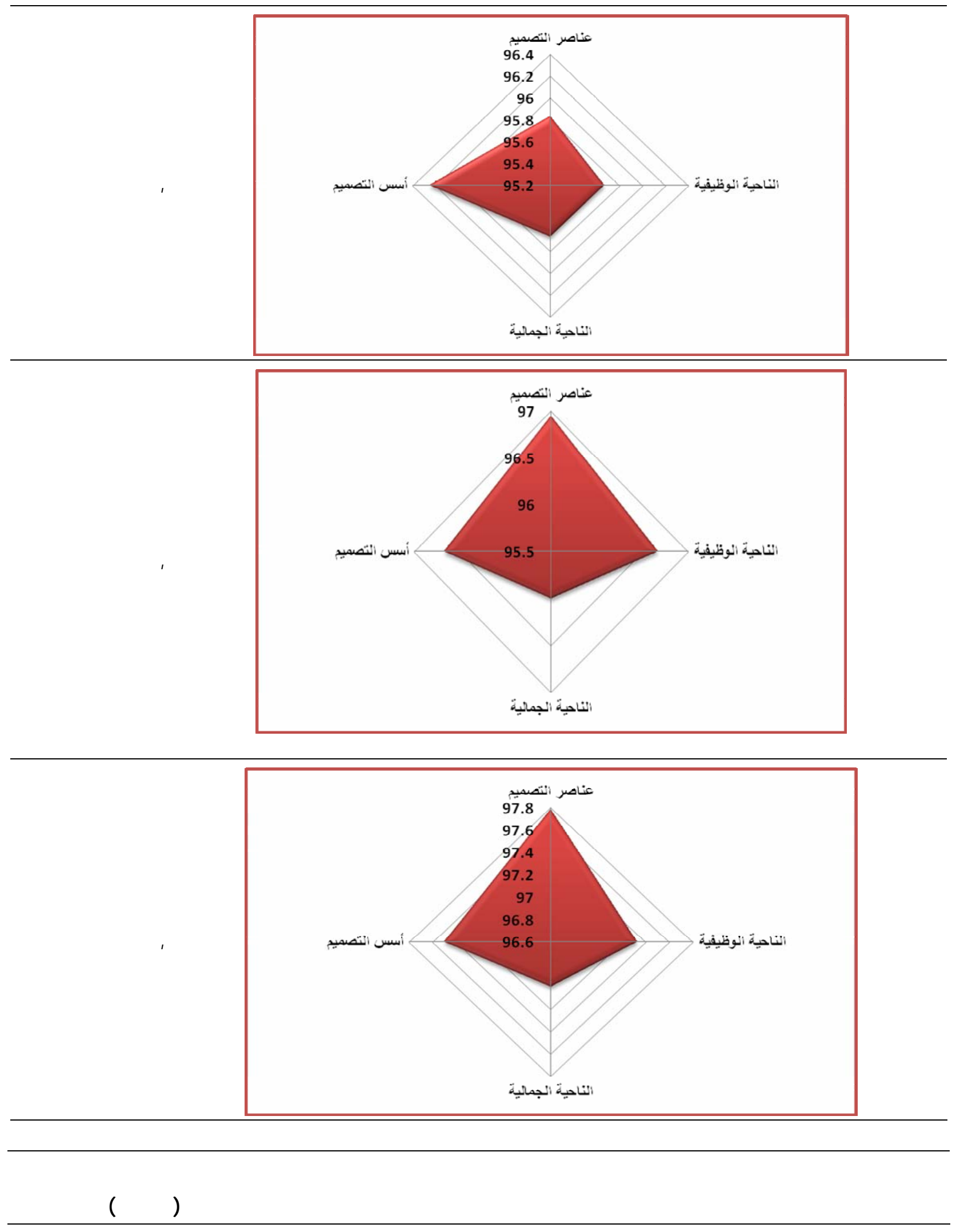




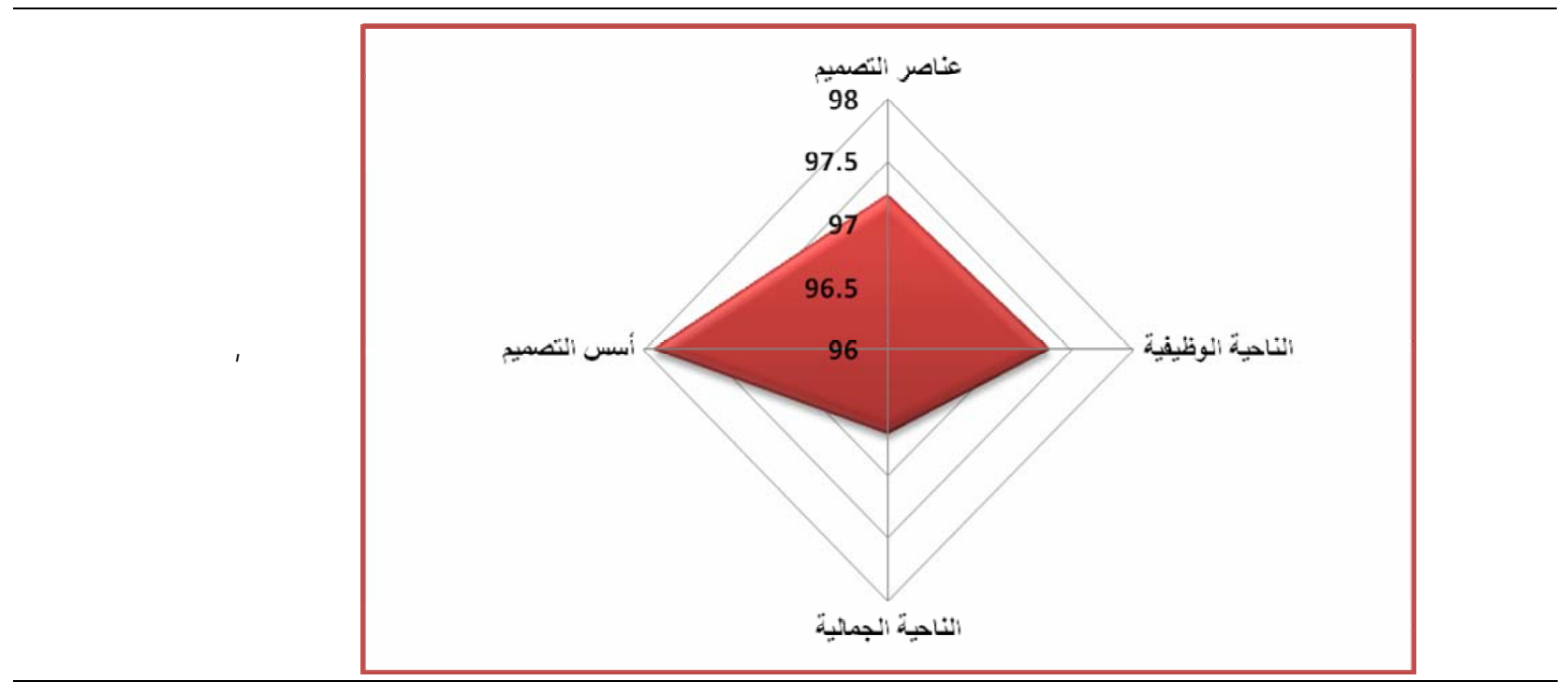

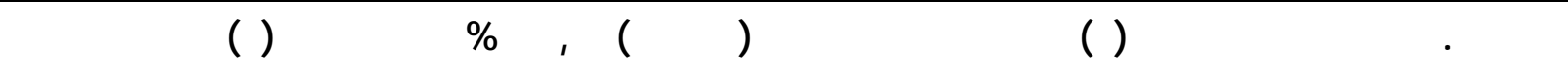

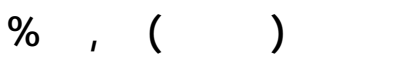

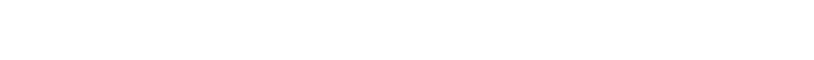
الخاملت المختلفة وقوة اللشد:

يتضح من الجدول رقم(10) وللشكل رقم(ع) أن:

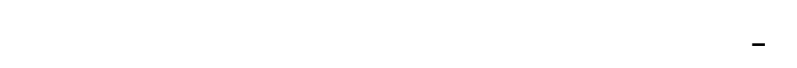

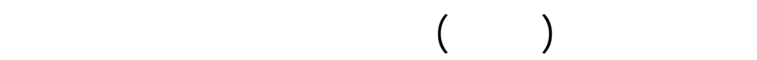
المقطع العرضي وكذك بها نسبة كتنان( •ع\%) والكت لن ان

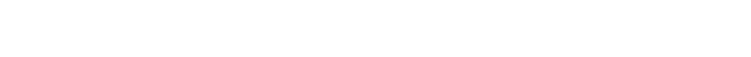

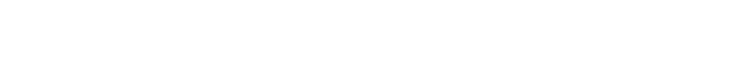
يؤوى إلى تملسكها وبالتالي ارفقاع متانتها.

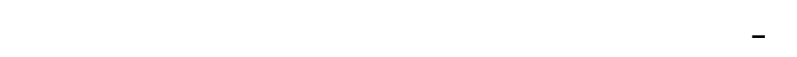

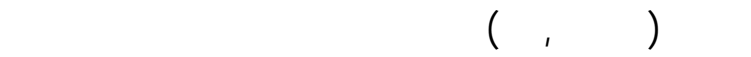

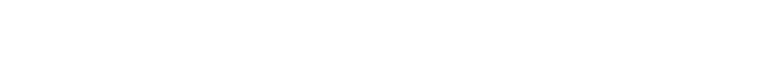
والاحتكك بين الشعيرات وبعضها ضعيف وكذك فو فـان زياة عدد البرمك للشعيرات القليلة في التط ـر يـ -ؤدى إلى ققصفها ويضعف من قوةشدها.
ثلنياً: نتنائج الختبارت المبيعية والميكلنكية المينات مطل

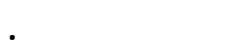

الملافة بن عينلت الفمشة المنتجة من بوافي خيطا الخاملت المختلفة وقاومة التمزق: يتضح من الجدول رقم (10) وللشكل رقم (س) أن:

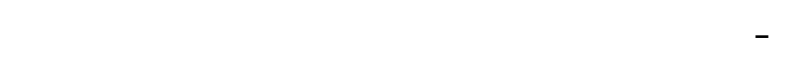
ذالك إلى أن النمرةسميكة وتحتوى على عدد كبيرهم ن

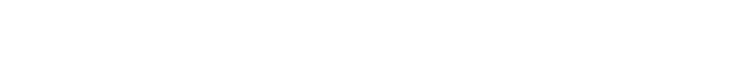
7 7 بولي لكريليك و. ع\% كتلن حيث أن الكتان عبارة كن حزم من من الشعيرات وليمتشعيرة مفردة وتربط الحزم ماة صمغية بين الشعيرات وبعضها تعمل على تملسكها وان اليف البولي لكريليك الف ـت ح ـول حزم الكتان مما أدى إلى متانتها العالية وشنة تملسكها.

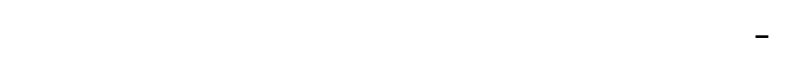
ذلك إلى أن النمرة الرفيعة بها عدد القل من الـ شعيرات في المظع العرضي وان قوة الاحتكك بين الـ شعيرات وبعضها ضعيف مما يؤدى إلى قلة مقاومتها للتمزق. جرل 10 ـ متومطلت الفراءلت اللختبارل اللبيعية والميكليكية 


\begin{tabular}{|c|c|c|c|c|c|c|c|}
\hline الإتقدكي الوزن نتيجة & المرنع المتر) & 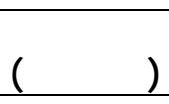 & الاستالة & قومة الشه) & التمزوقة & نمرة نالتج & العينة \\
\hline$\cdot, 19$ & एعO & $\varepsilon \cdot 90$ & $1 r, v 9$ & $\varepsilon\urcorner, \varepsilon$. & $9 \mathrm{~V} \cdot \cdot$ & 0 & 1 \\
\hline - & TVE & દ૦૧. & 10,17 & $\mu^{\mu \mu}, \Lambda$. & $\Lambda 7 V$. & $V, 0$ & $r$ \\
\hline$\cdot$, , हq & rq. & 0197 & $1 \cdot, \mu q$ & $\varepsilon \mid$ & $\Lambda \cdot 0$. & $\Lambda, 0$ & $\mu$ \\
\hline$\cdot, 119$ & rEO & $\mu^{\mu \mu} \varepsilon 0$ & $17, \varepsilon \varepsilon$ & $\mu \eta, \mu$. & Ar7. & 9 & $\varepsilon$ \\
\hline$\cdot, 11 \mathrm{~V}$ & rVE & દEV . & $1 \cdot, 0$. & $r \Lambda, r$. & Vาo. & $1 \cdot, 0$ & 0 \\
\hline
\end{tabular}

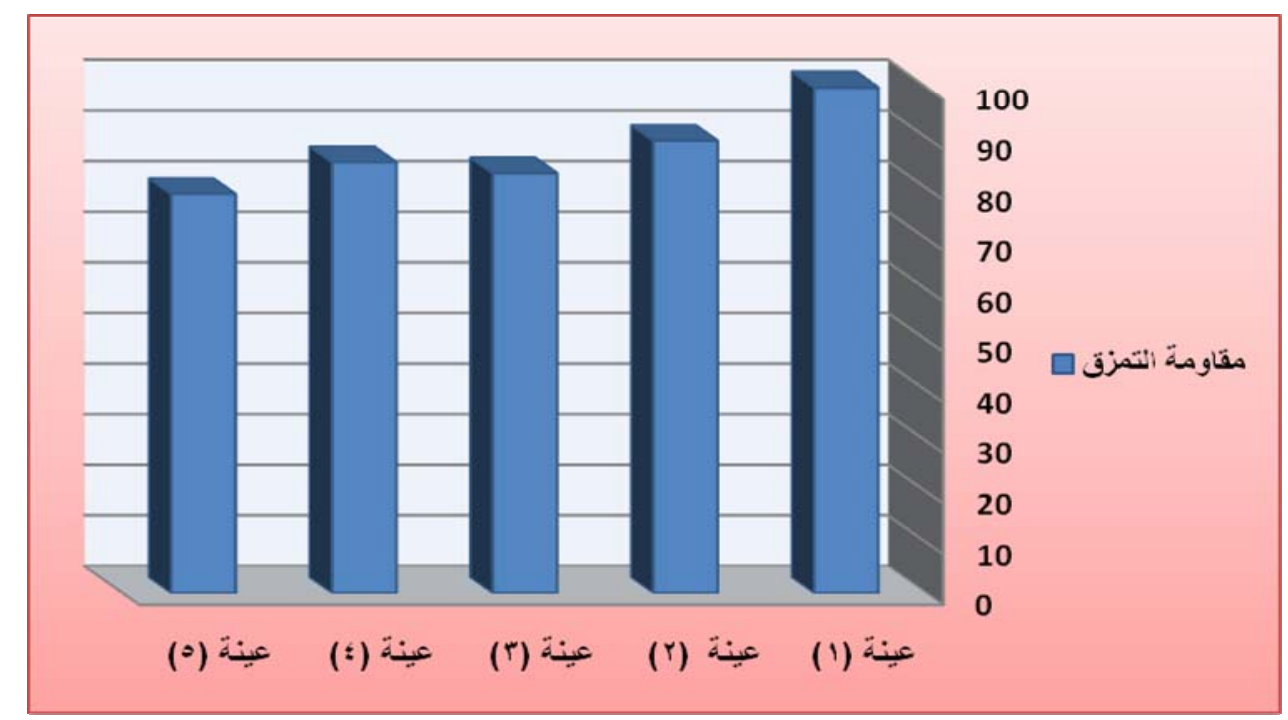

\section{شكل r. الملفة بين عينت الأفهة المنتجةمن بوالي خيوط الخامل المختلفة ومقاومة التمزق}

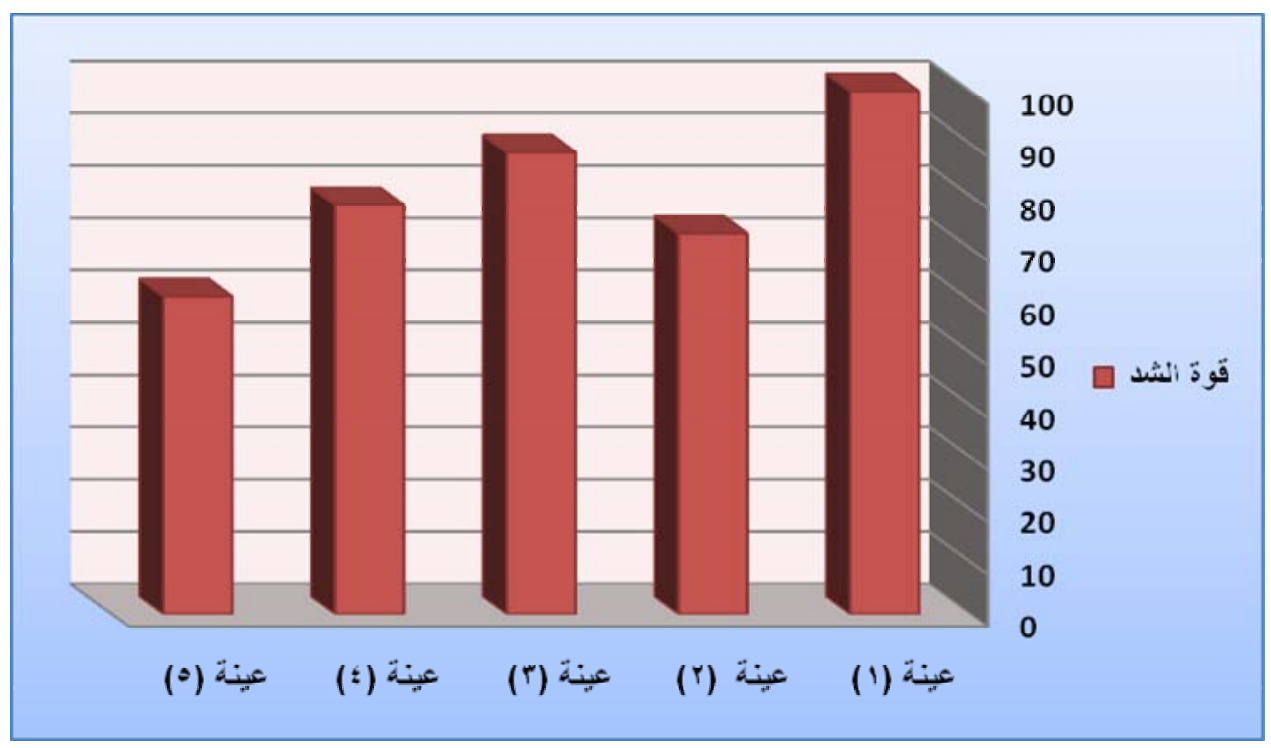

ششل ع. العلافة بين عينالت الففشة المنتجةمن بوالي خيطا الخاملت المختالة وقوة الشد 
صلابة الشعيرات مما يجعلها تق صف وقة ل ن سبة

السطالتها.

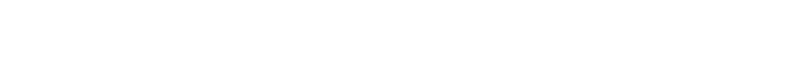

الخاملت المختلفة والصلابة:

يتضح من الجدول رقم (10) وللثكل رقم (7) أن:

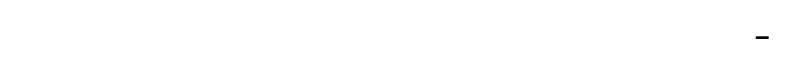

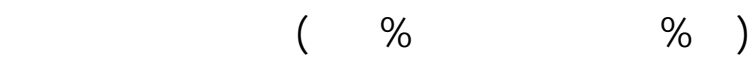

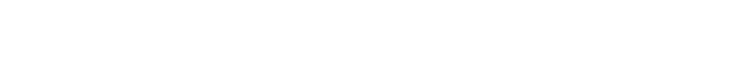
بمقدار عالي من المادة الصمغية التي تعمل على تملسك

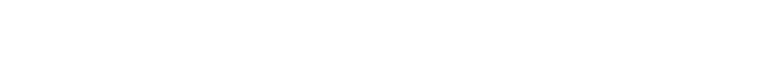

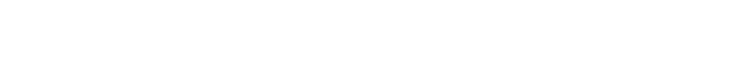
( • (1 درجة مئوي) يجعل جزء كبير من الماة الصمغية

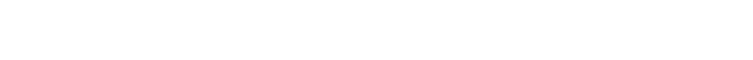

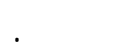
r - هقَت العينة الرالبعة القل درجة صلابة وهي مكونة من

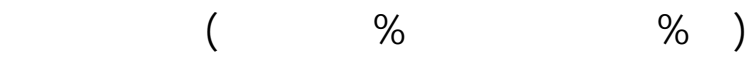
صناعيتلن تتميزان بالنعومة والمرونة ولا يحتويلن على الى مواد صلبة وان ما بهما من ص لابة هـ -و وج -ود البرملت التي تعهل على تملسكشعيراتها.
الملفة بين عينات الفهشة المنتجة مـ ن ب بولي خي ـط الخاملت المختلفة ونسبة الاقطالة: يتضح من الجدول رقم (0) والشكل رقم(0) أن: I - العينة الرالبعة حققت أعلى نسبة لسطالة ويرجع ذلك إلى

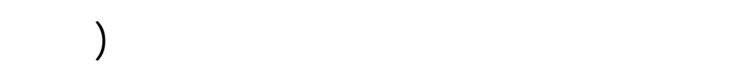

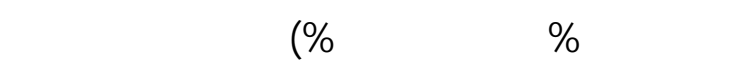

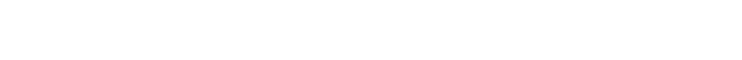

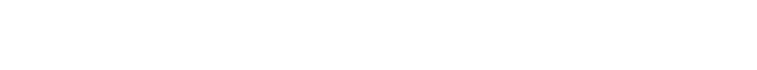
هو الأليف الصناعية فلن الثعيرات مة نظطيعها عل م.

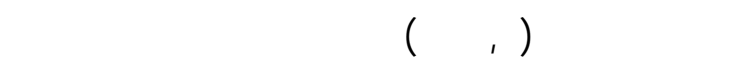

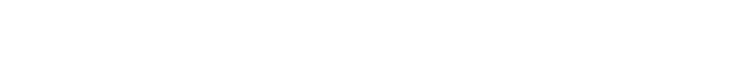
في الخلمتن بالإضلفة إلى أن نسبة المت صصاص الب ـولي

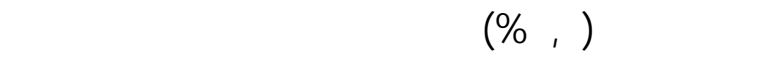
لذلك كلتت نسبة الإسطالة عالية عن بالقي العينات. r - العينة الثالثة والخلمسة حققتا القل نسبة لسطالة وذلك لان

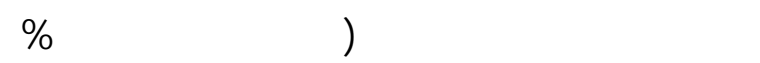

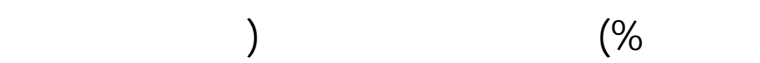

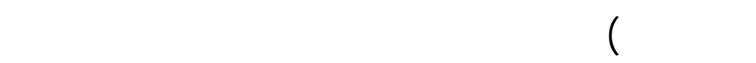

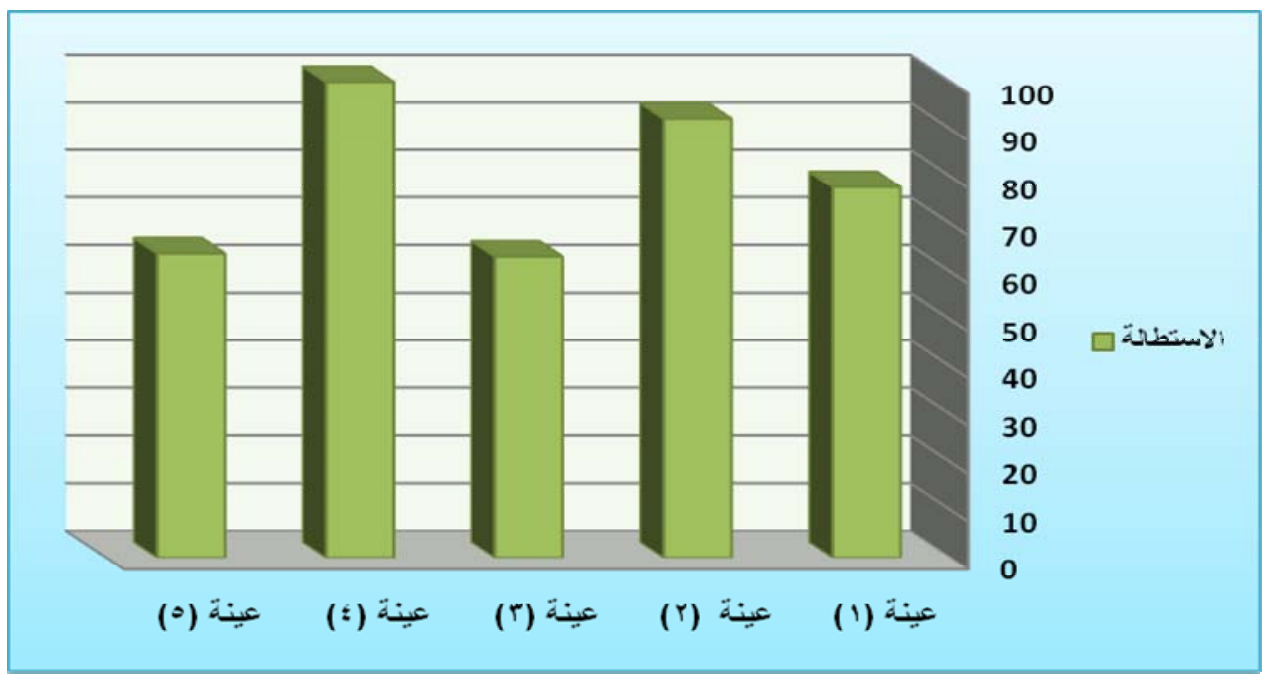

شكل 0. العلافة بين عينلت الأفهة المنتجةمن بوالي خيول الخاملت المختافة ونسبة للسطالة 


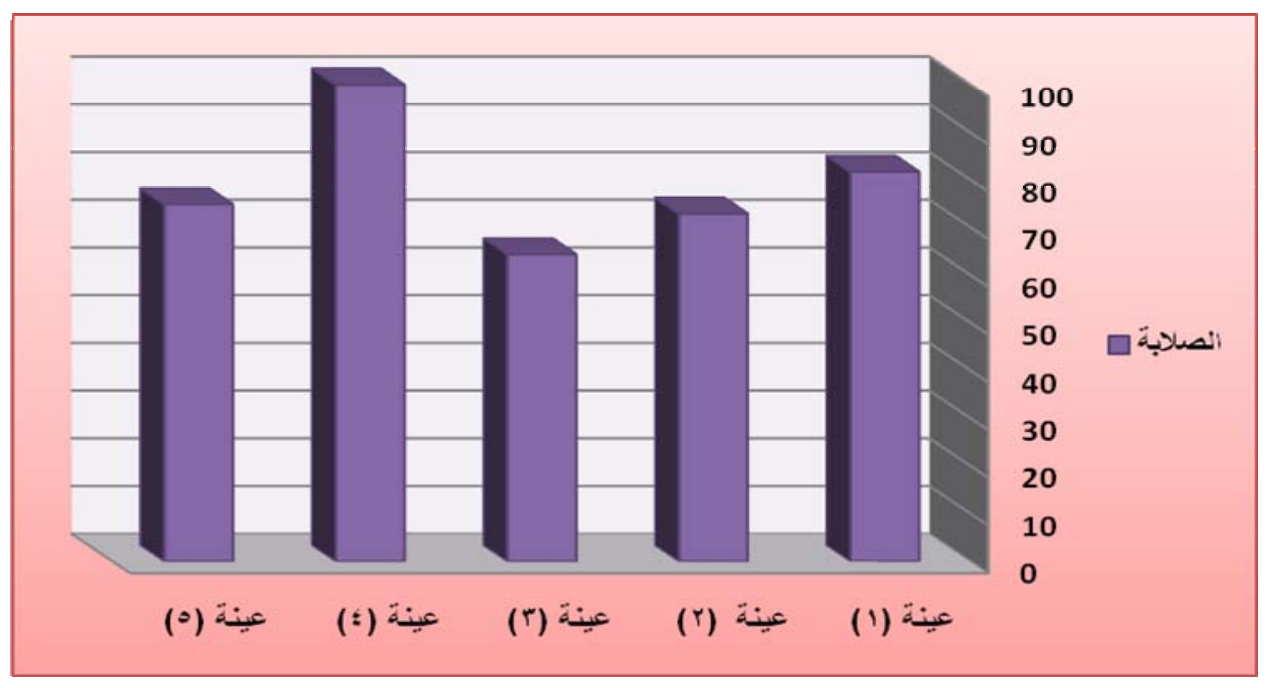

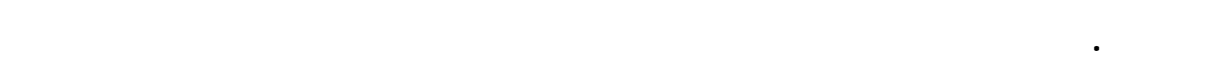

الملافة بين عينت الفمشة المنتجة من بولي خيطا الخاملت المختلفة والنقدف الوزن نتيجة اللحتكلك:

يتضح من الجدول رقم (10) ولالشكل رقم (^) أن:

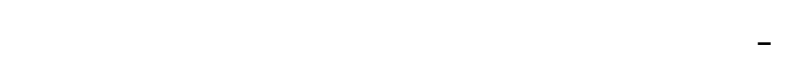

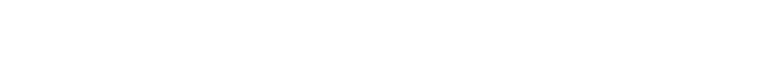
كبير من للشعيرات في المطعع العرضي وذات سطحح

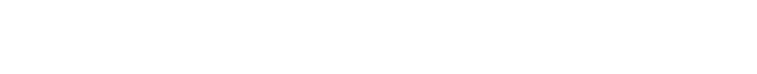

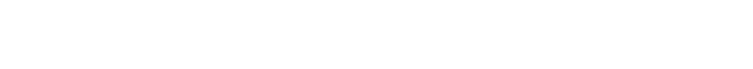
غير متملسكة ولذك فقدت نسبة عالية في الوزن نتيجة عام مقاومتها للاحتكك. r - همتت العينة الخلمسة القل نسبة فقد في الوزن نتيجة الاحتكك وذك لأنها ذات نمرة رفيعة وبها عدد قليل من التحن

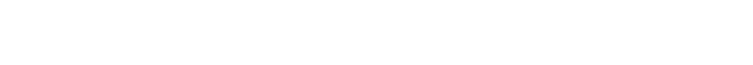
عالية تجطل سطحها غشن وان الفراغلت البينية بين الشعيرات وبعضها ضغعف ائ أن شعيراتها متملسكة النهات ولذك قاوم الاحتكك.

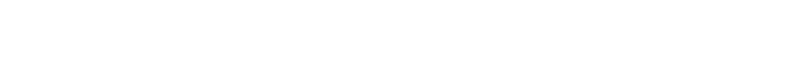
الخاملت المختلفة وونن المتر المريع: يتضح من الجدول رقم (10) ولشكل رقم (V) أن:

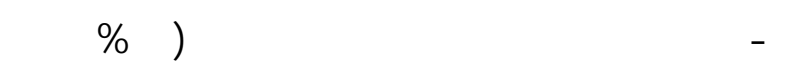

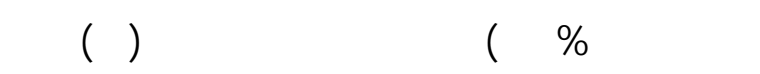
ذات نمرةسميكة وتحتوى على عدد كبير من اللشعيرات

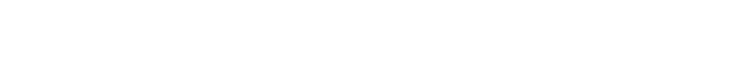

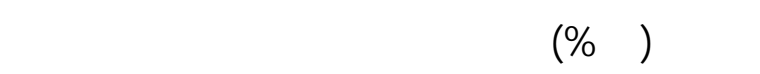

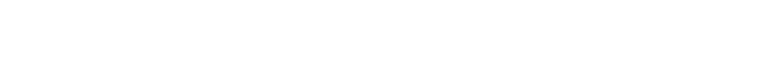

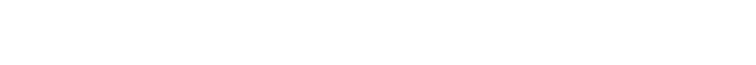

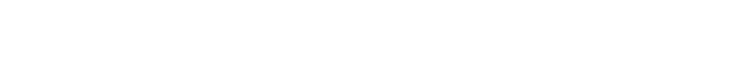

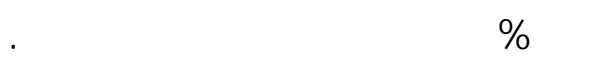

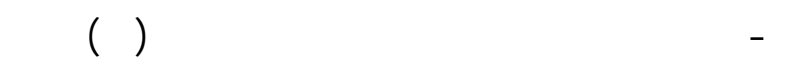

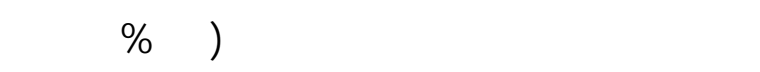

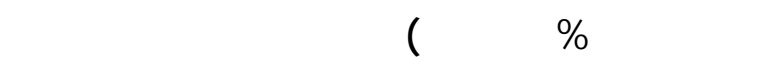

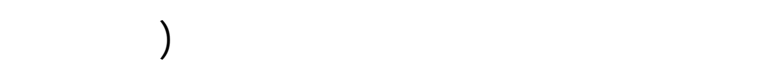

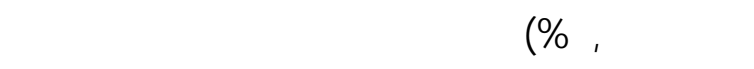

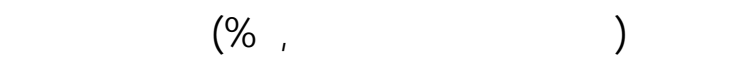

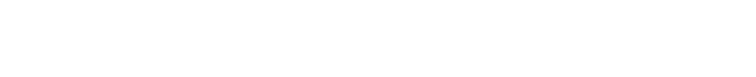
الرابعة لخف وزناًَمن باقي العينات. 



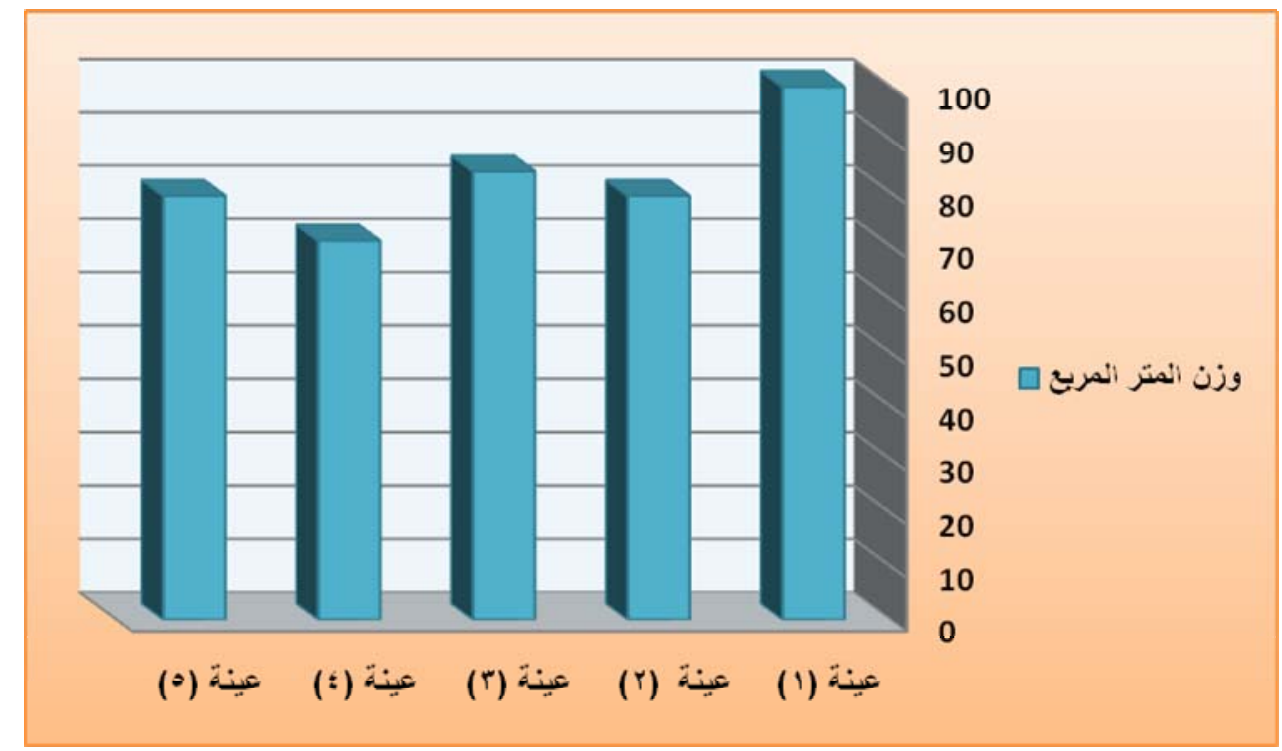

\section{ششل v. اللغة بين عينت الفمهنة المنتجة من بولف الخيوا وونن المنر المرع}

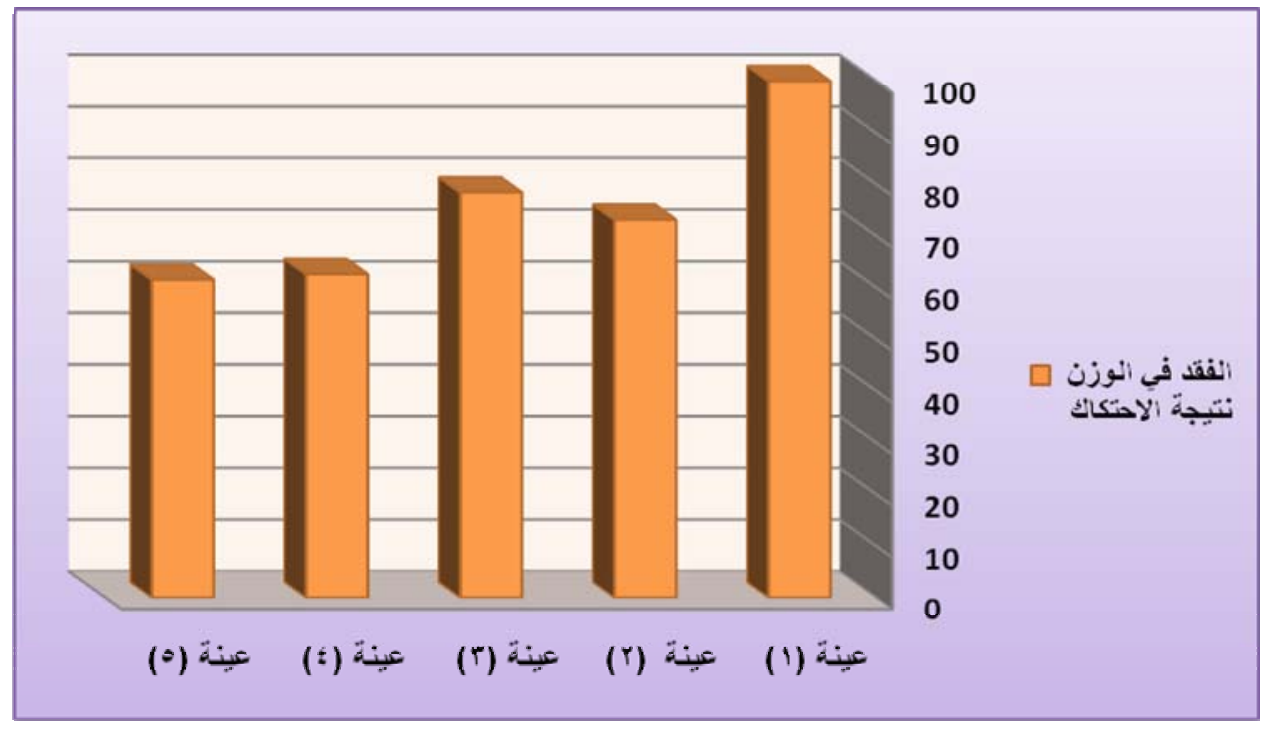

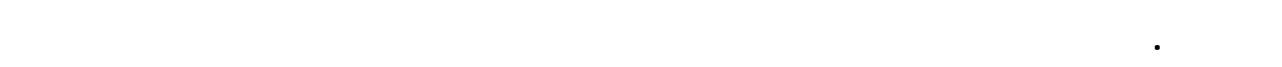

(79,人9)

العنصر الأكثر تأثيراً في الخواص المختبرة.

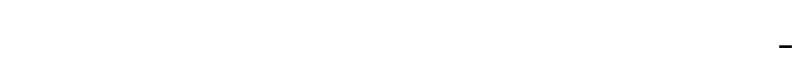

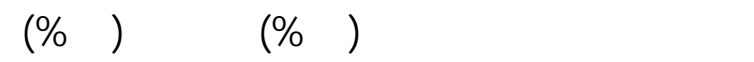

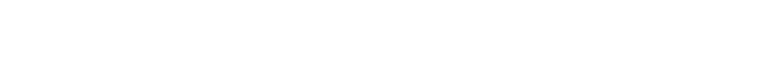

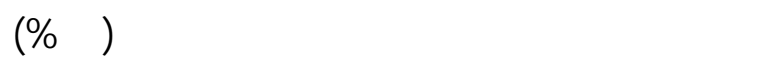

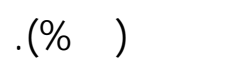

معالل الجودة الكلية اللعينلت المنتجة:

من الجدول رقم (17) وللشكل (9) يتضح ما يلي:

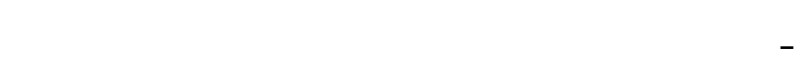

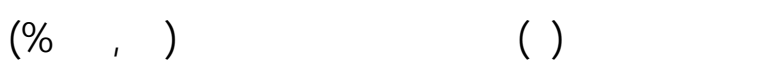

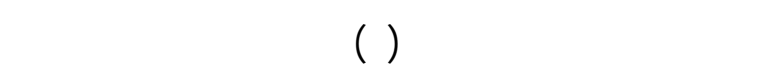

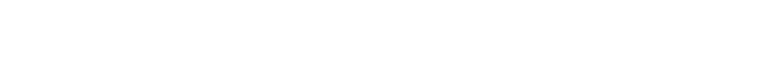





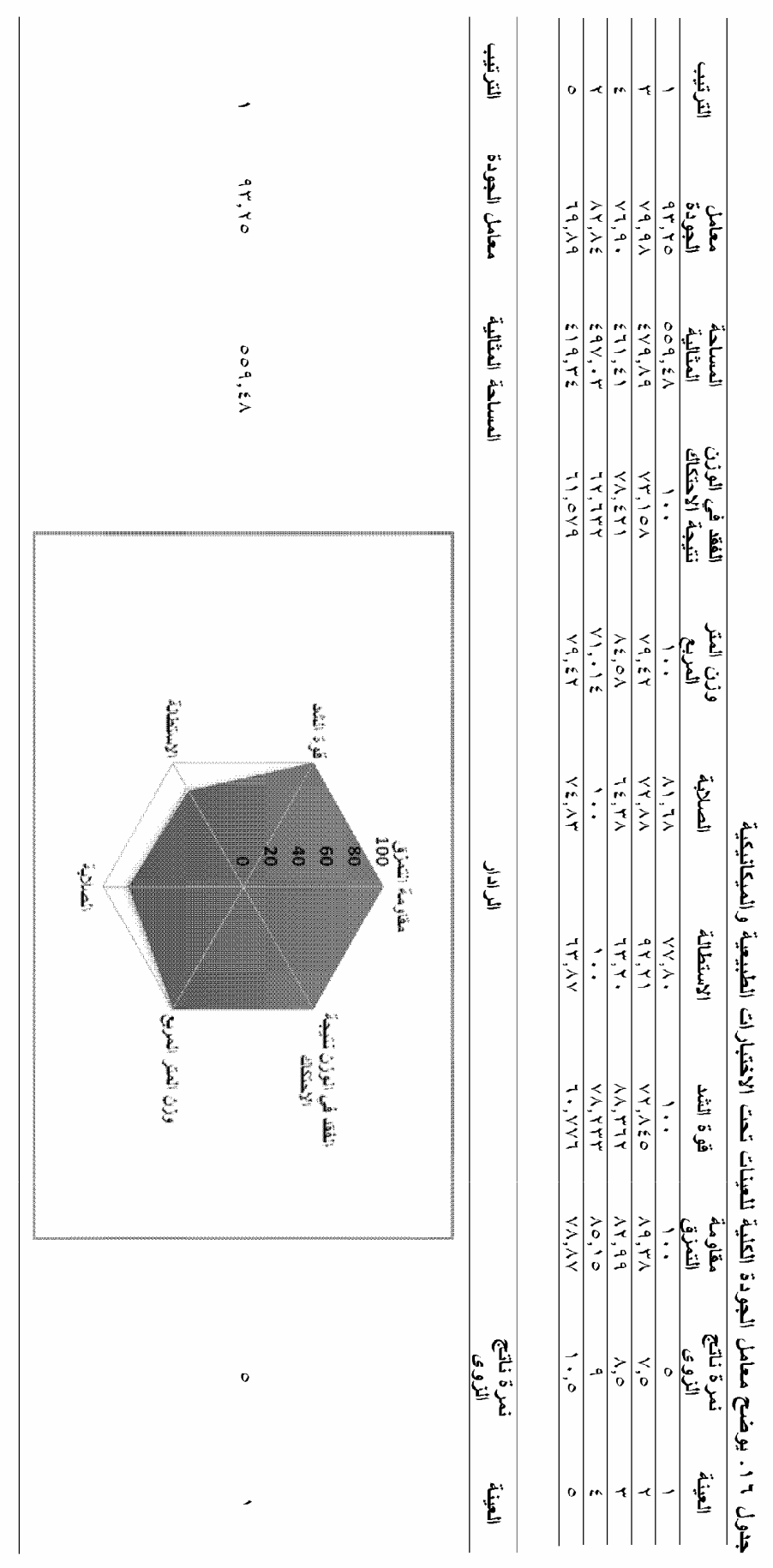




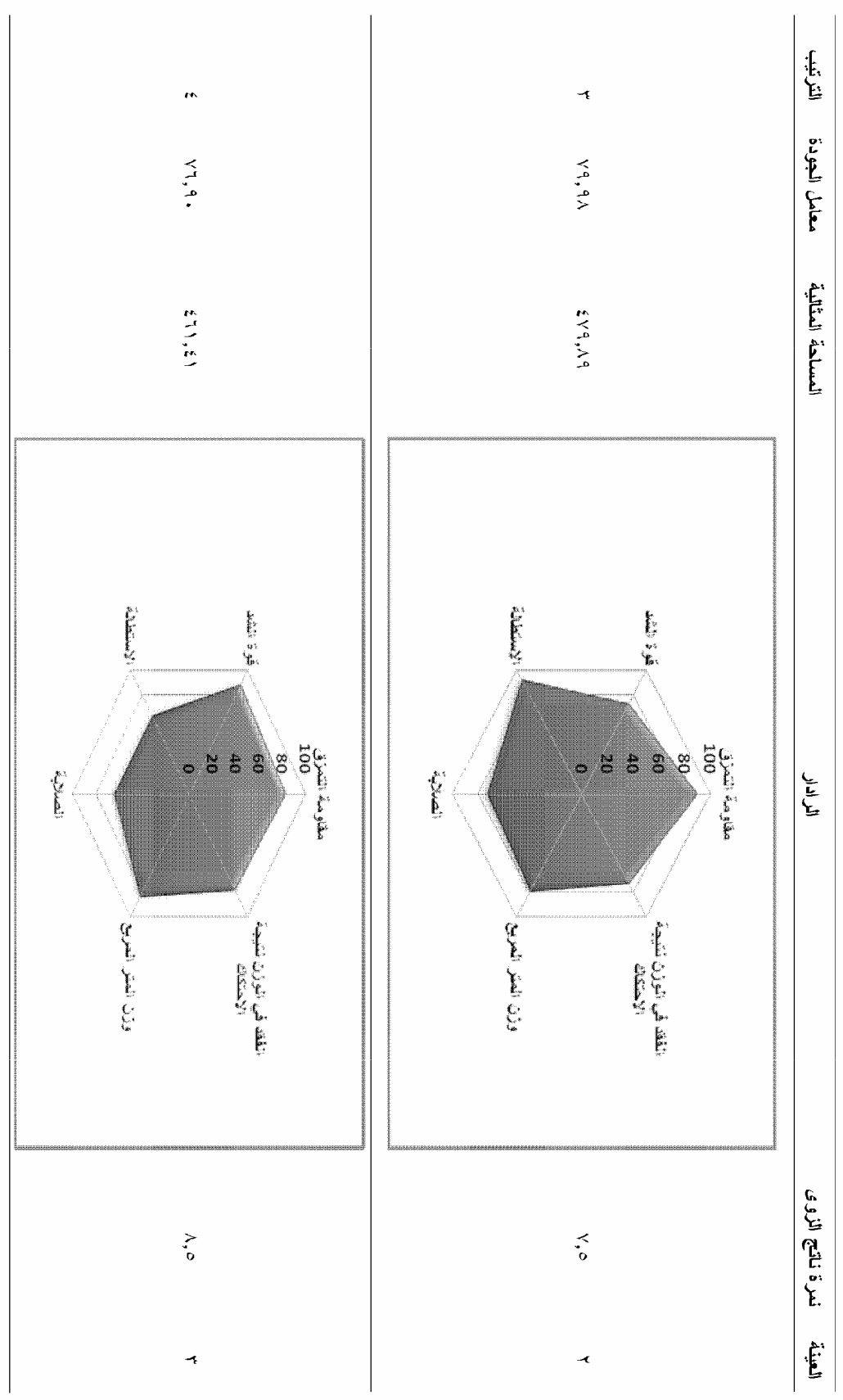




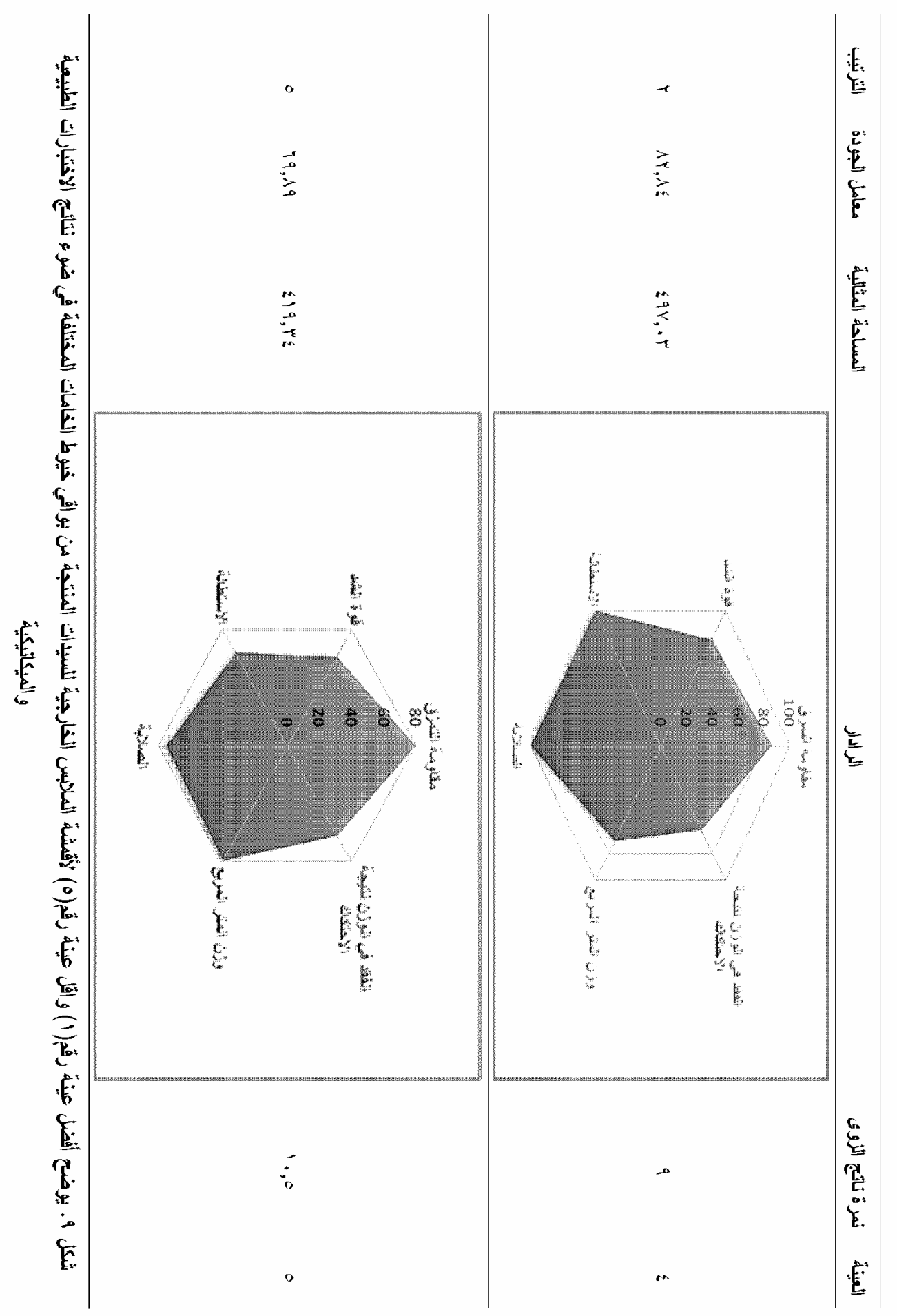




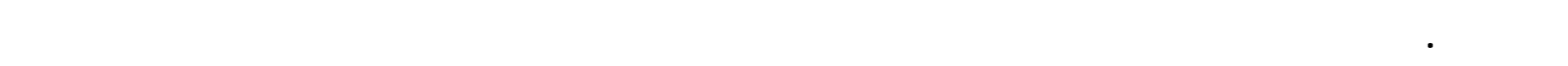

\begin{tabular}{|c|c|c|c|}
\hline معالل الرتبلا الرتب (سبيرملن) & لاختبارتب & المخكمين & العينت \\
\hline \multirow{5}{*}{ 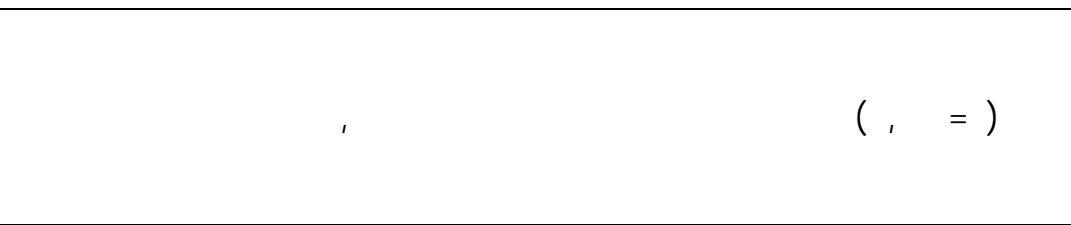 } & 1 & $\mu$ & 1 \\
\hline & $\mu$ & 0 & $r$ \\
\hline & $\varepsilon$ & $\varepsilon$ & $\mu$ \\
\hline & $r$ & 1 & $\varepsilon$ \\
\hline & 0 & $r$ & 0 \\
\hline
\end{tabular}

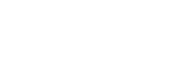

I - إبراهيم عبد الرحيم: إدارة الأعمل الصناعية، مكتب ـة ع ــن

ش شמس، 1999.

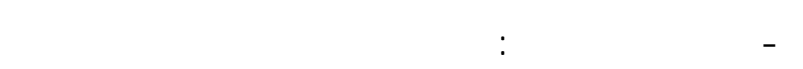

$$
\text { المعارف بالإسكندرية، } 1990 .
$$

ب - إنصف نمصر وكوثر الزغبه: درلسات في النسج، دار الفكر

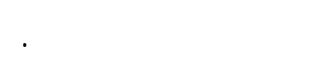

ع - ح سن ء ـوض الجذ ـدي: الإح ـصاء والحلس ـب الآل ي طبيقت IBM SPSS Statistics V21 الطبعة الأولي مكتبة

$$
\text { الأنجلو المصرية، القاهرة، عا ·r. }
$$

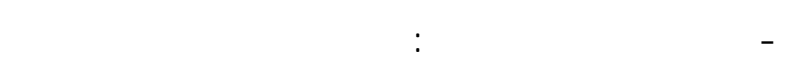

$$
\text { شמט، } 199 \text {. }
$$

7 - هسينسيد على معبد: تحقيق الأداء الوظيفي لأقمشة الب ـل

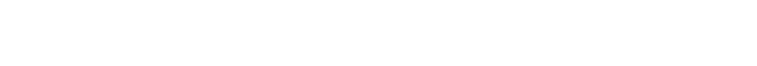
الزوى الحلقي، بسالة كتوره، كلية الفنون الطبيقية، جلمعة

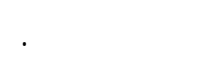

V V Vمير لحمد الطظاوي: تكنولوجيا إنتاج خيوط، كلية الفذ -ون

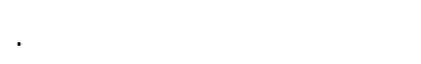

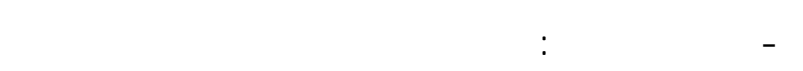

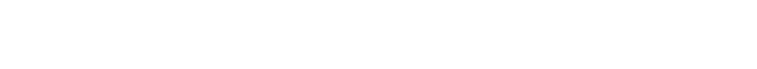

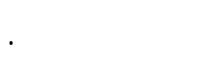

9 - علية عابنين: درلسك سـ يكولوجية الملاب س، دار الفك ـر

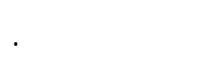

ثالثا:منالشة الملفة الارتبليه بين نتائج البهث في ضوء

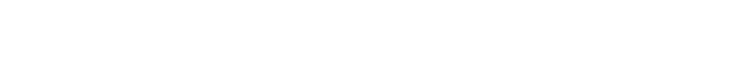

والميكانيكية:

الفرض الثامن: (توجد علاقة ارتبطيه بين ترتيب المحكمين للعينات وترتيبها في ضوء نت ائج الاختب ارات الطبيعي ـة المبنة

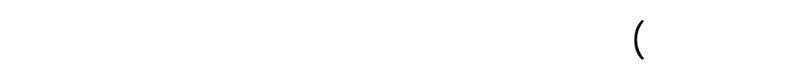

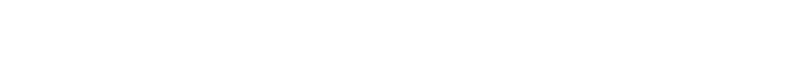

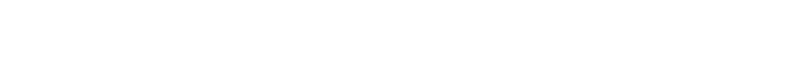
موضح بالجدول اللسابق.

\section{التوصيلت}

1 - ضررورة الاستقادة من بواقي خيوط الخلملت المختلف ـة

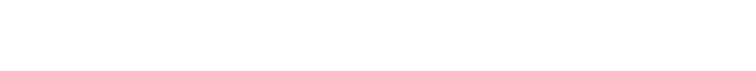

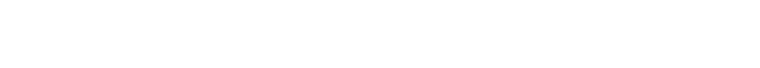

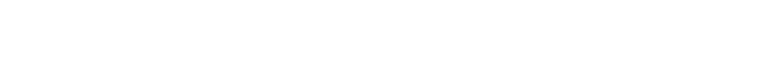
الخارجي.

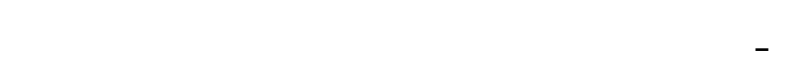

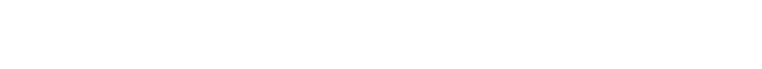

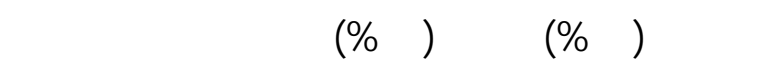

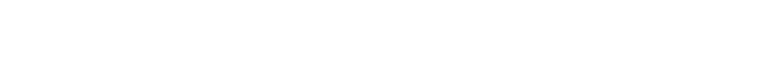
الإستخدل كملابس خارجية. س - إعاة لستعمل بواقي خيوط الخلملت المختلفة في إنتاج

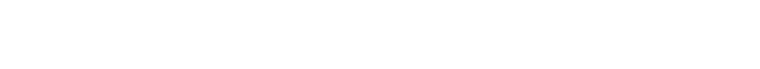

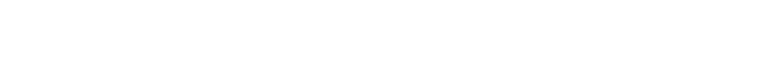

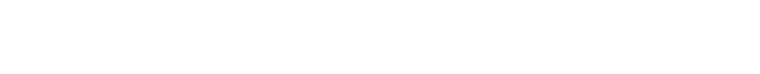
والمصانع وتعتبرسبب رئيسي في إهدار رلأس المل. 
14- Alon, G., and Alexander, E.: Mechanism of NEP FORMATION MELLI and Textile Berichte .p .p 865-1999.May 2000.

15- Arndd, E. : Looking at Design, London 1995.

16- Charlotte \& Petter fill: Design of The 20 Century, Susanne Hussmann-Cologne 1999.

17- http://www.swicofil.com/companyinfo/manual Twist direction html, search Date: 28march 2011.

18- Koppel man: Product marketing, Berlin 1989.

19- Kotler, Philip: Marketing Management Analysis Prentice-Hall-USA 1999.

20- Shwehart, W: Economic Control of Quality of Manufactured Product, D. New Yourk 2001.
• ا - عمرو حمدي الليث:معايير مبتك _رة بلب تخدلم ال ـزوى

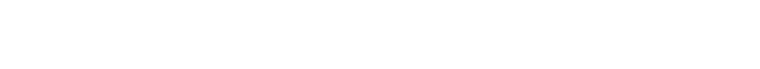

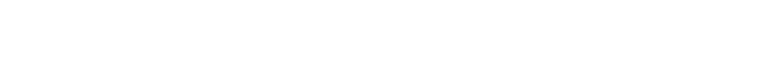

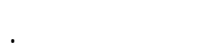

11 - محمد لحمدسلان: ألي لف الذ سبج، من شألة المع ارف، .199 .

rا - نبيل عبد البلبط: العلامة البيئية، لٔكاديمية البح ـث العلم مي

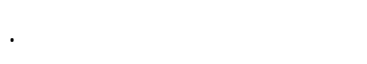

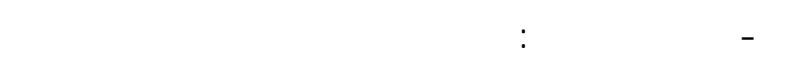

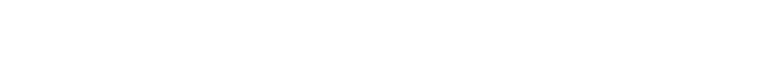
والمصبوغة، لسالة كتوره، كلية الفنون الطبيقية، جلمع ـة

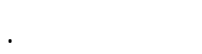




\section{Take Advantage of Leftover Yarns of Different Materials in Factories to Produce out Wear Clothing For Ladies Achieve the Aesthetic Appearance and the Functional Performance}

Amal Ahmed Mohamed Mahmoud

The search is designed to Take advantage of leftover Yarns of different Materials in factories to produce Out Wear Clothing for Ladies achieve the Aesthetic appearance and the Functional performance and using leftover yarn in the production of angled wefts (materials, spinning style, mixing ratio, colors, yarns counts) various types of fabric ladies Out Wear consumers with aesthetic values and specifications check the positive influence on the aesthetic and functional performance, as well as the economic side, Also produce all the twisted yarns samples and (5) of the individual yarns (leftover yarns) using a cabled loop and process these samples with different (materials, spinning style, mixing ratio, counts, colors) and use in several materials are: Poly-acrylic (60\%)+ Linen(40\%)Turquoise/Beige, Poly-acrylic (100\%)+ Cotton (100\%) Beige/white, poly-acrylic (50\%) + Linen $(50 \%)$ Red /Beige, Poly-acrylic (67\%) + Polyester (33\%) Red/Red, Poly-acrylic (50\%) + Linen(50\%) Grey/Beige, and used as wefts at( ELZAWY) factory in (ALSALAM) city Cairo.

(5) samples of fabrics were produced from twisted yarns and these samples produced by the Egyptian company for spinning and weaving Wool in (Imbaba), Cairo to take advantage of leftover yarns in the production of adequate functional fabric and the aesthetic and economic at the same time are with the invention. some laboratory tests conducted on fabrics is produced (Tensile strength, Elongation ratio, Weight loss as a result of friction, fabrics Stiffness, Resistant of Tearing, Weight per square meter) in laboratories, National Research Centre, Dokki- Cairo. A questionnaire designed was presented to a group of specialists in the field of Clothing and Textiles to determine the appropriateness of both materials, structure, threaded colors, clothes density, intensity aesthetic appearance, texture, decorative effects).

The main results were as follow:-

- Made clothing fabrics for ladies produced from different materials leftover yarns of the degree of acceptance and success in the light of the average assessment of arbitrators to the first axis of evaluation and design elements ranging between quality assessment $(95,83 \%$ and for sample(2), $97,78 \%$ and for sample number(4) and it is high ratio).
-Made clothing fabrics for ladies produced from different materials leftover yarns of the degree of acceptance and success in the light of the average assessment of arbitrators to the second theme of the evaluation, it found design quality rating ranging between $(96,25 \%$ and for sample(2) $97,92 \%$ and for the sample no. (5) and it is high ratio).

-Made clothing fabrics for ladies produced from different raw materials leftover threads of the degree of acceptance and success in the light of the average assessment of arbitrators to the third axis of evaluation and it is aesthetically ranging between quality assessment $(95,67 \%$, for sample (2), 97\% and for sample number (4) and it is high ratio).

-Made clothing fabrics for ladies produced from different materials leftover threads of the degree of acceptance and success in the light of the average assessment of arbitrators for the fourth axis of the evaluation and is functionally ranging between quality assessment $(95,67 \%$, for sample (2), 97, 33\% and for sample number(4) and it is high ratio).

Axis can be arranged in the light of the average ratings of the arbitrators as follows: Design elements, functional, aesthetic and design principles.

- The first sample has a higher Tensile strength and resistance to Tearing and the highest percentage of Weight loss as a result of Friction while the fifth sample gave less Tensile strength and resistance to Tearing and lowest weight loss due Friction.

- Had the fourth highest percentage of sample Elongation while the third and the fifth sample achieved the lowest Elongation.

-Achieved the third highest sample Stiffness while the fourth sample less Stiffness.

-The first sample has a higher weight per square meter, while the fourth sample less weight per square meter.

- Best sample no. (1) and lower sample no. (5) of the Out wear ladies clothing fabrics produced from leftover strands of different materials in the light of the results of natural and mechanical tests.

- A Correlation was Found between the arbitrators to order samples and arrange them in the light of the results of natural and mechanical tests. 